Article

\title{
Usability in Patient-Oriented Drug Interaction Checkers-A Scandinavian Sampling and Heuristic Evaluation
}

\author{
David Vingen *(D), Elias J. Andrews and Mexhid Ferati ${ }^{(D)}$ \\ Informatics Department, Linnaeus University, 39231 Kalmar, Sweden; elias.andrews@gmail.com (E.J.A.); \\ mexhid.ferati@lnu.se (M.F.) \\ * Correspondence: dvingen@gmail.com
}

Received: 10 September 2020; Accepted: 5 October 2020; Published: 9 October 2020

check for updates

\begin{abstract}
Drug interactions are an important source of medical error and a topic of particular interest to patient audiences. Patients must be informed to be able to participate in decision-making affecting their health. This paper explores the availability of drug interaction checkers in Scandinavia and the prevalence and characteristics of usability issues preventing patients from benefiting from them. Drug interaction checkers were sampled and evaluated through heuristic evaluations. Issue-based data were analyzed through descriptive statistics, as well as single-case and cross-case qualitative analyses. The findings were interpreted side-by-side using a mixed-methods approach. The results showed a multitude of usability issues. Catastrophic issues indicating the safety of dangerous drug pairings were found in two of the checkers. Results also showed that the checkers lacked adaptive design, patient-oriented content, and adherence to basic design principles. A positive correlation was observed between system complexity and number of usability issues. We suggest that this comes from a lack of systematic design approach. The market for Scandinavian drug interaction checkers was as such characterized by a limited selection of checkers known to be used by patients for their utility, but failing to accommodate them in terms of system quality.
\end{abstract}

Keywords: patient-oriented healthcare; drug interactions; usability; heuristic evaluation

\section{Introduction}

Medical error has been identified as a leading cause of avoidable harm [1,2], and patients outside hospitals have been shown at particular risk of drug-related medical errors [3]. Failure to prescribe necessary drugs, patients failing to adhere to drug treatment, or intoxication caused by drug interactions are all examples of such errors. Many of these errors are preventable, and nearly half of all preventable adverse drug effects have been shown to be serious enough to cause hospitalization. The errors frequently occur in phases of prescribing or monitoring drug use. This highlights the importance of safety interventions in these stages of outpatient care [2,3].

Drug interactions are when concurrent use of multiple drugs, a drug and a food, or a drug and a beverage causes changes in the effects of a drug. Such changes may consist of the appearance of side effects, or in the suppression of desirable effects. The likelihood of drug interactions increases with the number of drugs taken. This also often correlates with age. Up to $7 \%$ of hospitalizations have been shown attributable to drug interactions [4].

Polypharmacy means concurrent use of multiple drugs, which also applies to taking more than one drug for a single condition. Increased use of drugs has important health benefits, but polypharmacy increases risk of drug interactions. Åstrand et al. [5] conducted a cross-sectional study of drug prescriptions in Jämtland, Sweden, over a period of 30 years. They found a pronounced $61 \%$ increase 
in polypharmacy, and found the risk of potentially interacting drugs strongly correlated with this increase. Hovstadius et al. [6] looked at the development of polypharmacy in a 4-year period between 2005 and 2008. Using the Swedish Prescribed Drug Register they were able to analyze data over the entire Swedish population according to drugs prescribed per individual. Applying a definition of polypharmacy as receiving five or more prescription drugs during a three-month period, and of excessive polypharmacy as receiving ten or more drugs within the same period, they found an $8 \%$ increase in polypharmacy, and a $16 \%$ increase in excessive polypharmacy. The study showed a steady increase in polypharmacy, excessive polypharmacy, and drug use in general, in spite of the well-known risks to patient health [6].

Lack of adherence to treatment is a frequent source of drug-related medical error. Non-hospitalized patients have greater influence over their adherence to drug treatment, making them central in the prevention of medical errors [3]. Patient-centered care and patient participation have been recognized as important means of improving adherence, and have also been recognized as means of increasing health-literacy and improving patient safety and satisfaction. When patients are able to self-manage their symptoms, this leads to more efficient healthcare, and also improves the quality of life. Participation is achieved by facilitating active engagement in decision-making. Achieving this requires that caregivers respect patients' knowledge of their own bodies, and regard this knowledge as complementary to their professional knowledge. Participation also requires empowering patients with the information and the resources that enable them to participate [7].

Assuming a patient-centered perspective on drug treatment suggests exploring patient needs for information regarding drugs. Kusch, Haefeli and Seidling [8] investigated patients' desires for drug information through a systematic literature review sourcing studies on patients' drug information needs as well as studies on patient inquiries to drug information services. Topics were identified, and their frequency of occurrence was calculated. The results consistently showed adverse drug reactions and drug-drug interactions as the most desired topics. Discussing their findings, Kusch et al. [8] indicated the need for making drug information more accessible to patients. To do so, they suggested building information databases based on patient-oriented topics, such as those identified by themselves.

In Scandinavia, much work has been undertaken to develop information systems for drug information and drug interactions. Such systems help healthcare professionals navigate large and constantly revised amounts of drug information. Böttiger et al. [9] discussed the Swedish Finnish Interaction X-referencing database (SFINX), a predecessor of the current Janusmed [10], describing the integration of its database with Swedish and Finnish healthcare systems to serve thousands of physicians and pharmacists. A subsequent study [11] looked at the impact of SFINX in primary healthcare centers. The study compared 15 centers where the SFINX system had been implemented with 5 centers where it had not. The centers where the system had been implemented showed a significant reduction in prescriptions leading to serious drug interactions [11].

Janusmed is today freely available as a web-based service. Although developed for a professional audience, rumors caught the attention of Nörby et al. [12] that pregnant women had also adopted the site. This prompted them to investigate the pregnant women's experiences of using the Drugs and Birth Defects section of the service. The findings showed that $11 \%$ of the women were already familiar with the service in advance of their participation in the study. They also reported using several other information resources about drugs related to pregnancy. Some became more anxious from accessing the content, but the vast majority found the information valuable and easy to understand. They also found it to confirm and support information provided by healthcare professionals. Nörby et al. went on to suggest that communication and patient compliance might improve if patients and professionals referred to the same sources [12].

mHealth is meanwhile emerging as a promising means of delivering patient-oriented healthcare outside hospitals. mHealth is short for mobile healthcare, meaning the delivery of healthcare services and information through mobile devices. The mobile platform allows flexible and ubiquitous access to online and offline services and information. It therefore lends itself in particular to outpatient 
needs, and to individualized and patient-oriented services [13]. mHealth applications have been found to have been implemented predominantly through experimentation with technology rather than through strategic planning [14]. At the same time, these systems impact human lives on a large scale, potentially reaching millions of users and directly affecting their health. Just as it is imperative that information be accurate, it is also imperative that mHealth services not lead to user error, and thereby to adverse health effects [13].

Usability in critical systems can be a matter of life or death. Nielsen [15] commented on Koppel et al. [16], identifying 22 ways that automated hospital systems could result in the wrong medication being dispensed to patients. Nielsen [15] identified most of the problems as well-known usability issues that had been understood for decades. In a similar vein, Reolon et al. [13] showed that studies on healthcare systems have found significant usability problems inviting a range of human errors. These were found to have the potential to lead to injury or even death. Within mHealth they likewise found a range of usability problems as well as a lack of user-centered design. They argued that patient-oriented systems would likely be in particular need for usability due to a lack of training as well as a significant proportion of elderly users.

\section{Research Objective}

Usability studies have begun to appear within eHealth and mHealth [13,15]. More recent advances $[17,18]$ have developed and validated instruments for self-reported usability. To some extent, these have also been adopted in practice $[19,20]$. The usability testing that is needed to collect self-reported metrics is, however, known to be resource intensive. Heuristic evaluations have meanwhile proven to be particularly cost-efficient in driving the design improvement [21]. Research on the use of heuristic evaluations within mHealth shows papers on the topic to be sparse [13]. Adam and Vang [22], meanwhile, conducted an expert-based checklist evaluation on drug-drug interaction websites, measuring information capacity, patient usability and readability. No studies appear to have been conducted specifically on the quality of user interfaces in terms of usability for patient-oriented drug interaction checkers. The objective of this paper has therefore been to explore the prevalence and characteristics of usability issues facing patients using publicly available drug interaction checkers in the Scandinavian market. This was conducted to facilitate future improvements to this emerging market, and to raise awareness of the usability issues users face today.

Two research questions have guided the study:

1. What drug interaction checkers are available to the Scandinavian public today?

2. What is the prevalence and characteristics of usability problems in these checkers?

We delimited the context of exploration to the Scandinavian market in order to facilitate relevant and actionable insights. We also delimited it to drug interaction checkers accessible on mobile platform in order to appreciate the promise of mHealth for patient-oriented and outpatient uses. We did so also to stress usability requirements, seeing that mobile platforms place additional demands on usability.

\section{Related Work}

Patient-centered healthcare aims to empower patients and involve them in decision-making. This has been shown to lead to better engagement and adherence to treatment, causing better health outcomes. Allowing patients to participate requires informing them according to their own abilities and needs. As a means of promoting patient-centered healthcare, Kusch, Haefeli, and Seidling [8] conducted a scoping review in order to investigate patients' desires for drug information beyond that most basic and mandatory to be able to conduct drug treatment. This was done through a literature review sourcing studies on patient inquiries to drug information services, in addition to qualitative studies on patients' needs for drug information. Topics were independently extracted from the two sets of studies and subsequently integrated in a coherent set of topics. Frequency of occurrence was determined for each topic, and further analyses were conducted to assess the potential for 
individualization of the most frequent topics. Both sets of studies showed predominant interest in safety-related topics, with adverse drug reactions and drug-drug interactions figuring as the most frequent topics regardless of country, setting, or study design. Discussing the results, Kusch et al. [8] highlighted the diversity and nuances of information about adverse drug reactions and drug-drug interactions and how this suggests the need for individualization. There are for example patients whose adherence to drug therapy declines with the mere mention of adverse drug reactions, but there are also patients demanding every piece of information regardless of likelihood of occurrence. Kusch et al. [8] suggested the need for making drug information accessible and individualized for patients. Generating drug information databases based on patient-oriented topics was suggested as an initial step. They added that extensive research has been done on system quality of professional drug-drug interaction checkers, but that little has been done on similar checkers directed at patients [8].

Adam and Vang [22] conducted evaluations of content and patient usability in patient-oriented drug-drug interaction websites. This was done to investigate whether information on publicly available websites was valid and accurate, and to evaluate the capacity of the websites to address laypersons. Information capacity, patient usability and readability were assessed using an expert-based approach with grading scales. Websites with drug-drug interaction checkers were sampled using the Google search engine supplemented by suggestions from clinical practitioners. Sites had to be freely available without payment, and had to provide drug-drug interaction checking functionality capable of identifying the drugs applied in testing. Sites in languages other than English were excluded. Information capacity was assessed using a grading scale awarding one point for the presence of each of the features of alert for drug-drug, drug-food, and drug-alcohol interactions, presence of severity grading, and therapeutic duplication. Patient usability was assessed based on the presence of alert icons, color coding, severity rating scale, medication pick list, and the ability to store a profile account. Patient readability was assessed using the Flesch-Kincaid grading model, as well as the Flesch Reading Ease score [22]. The results showed that the majority of websites were not optimally patient-oriented due to poor information capacity and limited readability. The authors found many features missing in many of the checkers, and found information difficult to interpret. Half of the websites did not provide any severity ratings, while those that did, demonstrated substantial variations [22]. Adam and Vang [22] recognized a lack of validation of the grading scales applied. They also recognized the lack of patient involvement, pointing to practical problems of involving patients with their actual drug regimens. In conclusion, they found that further research is necessary to improve patient-oriented drug-drug interaction information systems [22].

Highlighting heuristic evaluations for their cost-efficiency, Reolon et al. [13] investigated the state of the art of heuristics-based usability studies in mHealth. They argued the need for adapting sets of heuristics both for mobile platform and for the domain of healthcare, aiming to investigate to what extent such adaptations have been made. They conducted a systematic literature review of articles published between 2007 and 2014 mentioning heuristic evaluation of mHealth applications. Applying their selection criteria on title, keywords and abstract, and then through full-text analyses, it reduced results to only seven articles, showing a need for more research on the topic. Contrary to expectations, the results showed studies predominantly applying traditional heuristics, such as those of Nielsen [23]. Four out of seven studies applied them as-is or only lightly modified. Only one study applied heuristics adapted specifically for the mHealth context [24], while another two applied Nielsen's heuristics adapted for mobile context [25]. Analyses of the heuristics applied showed considerable similarities converging on Nielsen's heuristics, suggesting these to be sufficiently generic to cover usability independently of device or application. A tendency was, at the same time, identified towards supplementing Nielsen's heuristics with domain specific or platform specific ones [13].

\section{Materials and Methods}

To attain reliable and valid results, we referred to frameworks for planning and conducting usability studies [26-28]. The scope of this paper was to investigate user interface-related usability as 
experienced by a general public of laypersons. Following from the research objective, our aim was not to assess drug interaction checkers according to any benchmark or predefined goal, nor to generate any kind of ranking. Rather, we wished to provide an explorative account indicating actionable areas for improvement. Even if the checkers evaluated were publicly released, the market as a whole was considered immature. Evaluations were as such formative with the goal of driving design improvement. Issue-based metrics, meaning qualitative and quantitative data based on the detection of usability problems, were applied to support problem discovery and comparison of alternative designs [26]. Performance metrics and self-reported metrics were ruled out because these depend on user testing. User testing across multiple systems would require significant recruitment to avoid the risk of learning effects. Involving representative users with their personal drug regimens would also pose both practical and ethical challenges surpassing the scope of this paper.

As is commonly recommended in usability studies, we chose a mixed-methods approach, collecting both quantitative and qualitative data based on heuristic evaluations. These were integrated through analyses for triangulation and enhanced understanding of usability problems faced by users [29]. The specific design chosen was that of convergent mixed methods, gathering both qualitative and quantitative data for independent analysis and subsequent side-by-side interpretation. Single-case analyses were conducted to identify themes of usability issues within each checker, and cross-case analyses were done to shed light on themes common for the Scandinavian context of drug interaction checkers. Both served the purpose of generating actionable insights for developers and decision makers. The study design is illustrated in Figure 1 below.

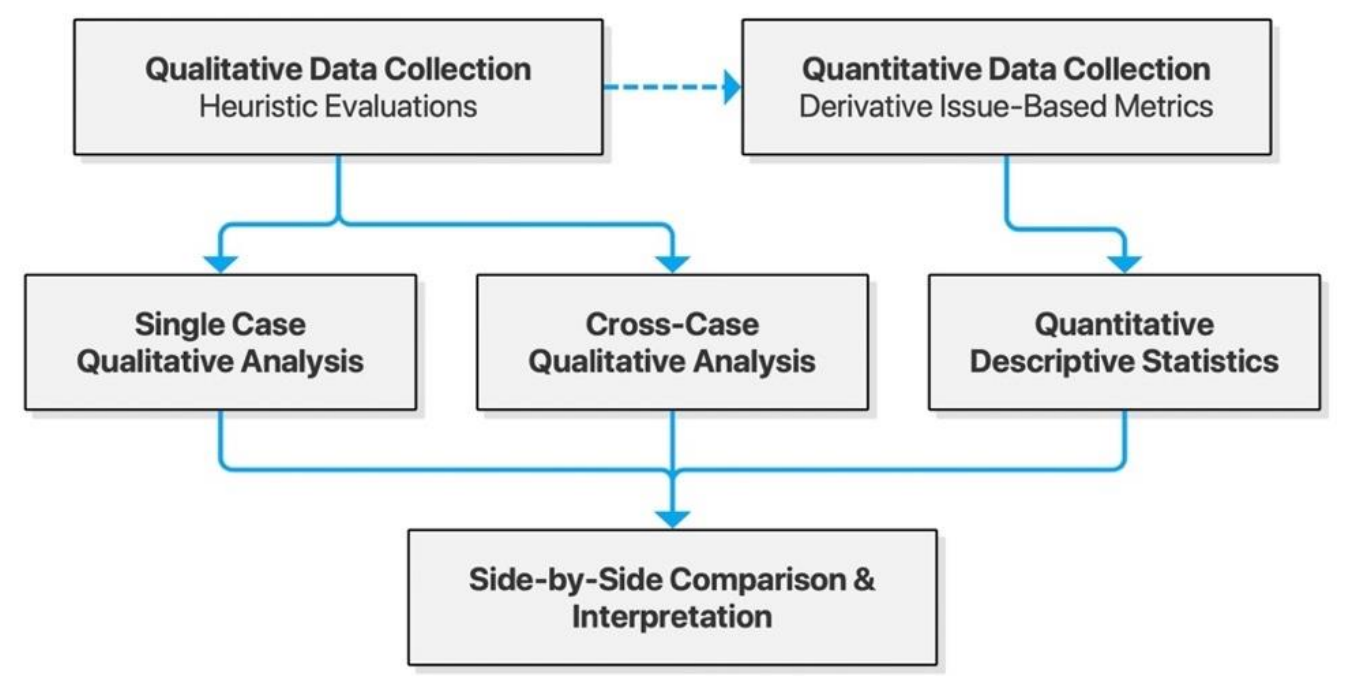

Figure 1. Model of the convergent mixed-methods study design.

\subsection{Sampling of Drug Interaction Checkers}

We performed a sampling to answer the first research question of which interaction checkers are available to the Scandinavian public today. To identify publicly available drug information systems likely encountered by patients, we identified the current leading health category websites for each country of Denmark, Norway, and Sweden. These were used to find popular matches using the Similarsites.com website similarity service [30]. Websites providing a match of more than $80 \%$ similarity to the sites based on category, content, word usage, and search terms were selected. The results were supplemented by websites suggested by clinical practitioners in these three countries. We then applied several exclusion criteria. The drug interaction checkers had to be freely available to the public and had to be aimed at Scandinavian audiences. In order to know which websites fit the criteria, we examined each website's main page for information about drug interactions. We then queried the website's 
internal search for the terms "interaction" and "drug interaction" in the local language. Results were then reviewed for resources on drug-drug interactions.

\subsection{Heuristic Evaluations}

Having identified available drug interaction checkers, we evaluated these according to the method of heuristic evaluation [28,31]. To accommodate different task flows across checkers, we defined tasks in terms of end-goals rather than specified steps. The three tasks applied are presented in Table 1.

Table 1. Goal-oriented tasks applied in heuristic evaluations.

\begin{tabular}{ll}
\hline \multicolumn{1}{c}{ Task No. } & \multicolumn{1}{c}{ Description } \\
\hline Task 1 & Find out whether drug X and drug Y produce adverse interactions. \\
Task 2 & $\begin{array}{l}\text { Find out which adverse reactions drug X may produce. } \\
\text { (i.e., with or without any other drug or substance.) }\end{array}$ \\
Task 3 & $\begin{array}{l}\text { Find out which adverse drug interactions a patient is exposed to, based on a } \\
\text { list of multiple drugs. }\end{array}$ \\
\hline
\end{tabular}

The drug pairings applied for the tasks were adapted from Adam and Vang [22], who identified five clinically significant drug-drug interaction pairs with a broad coverage of key therapeutic areas. We consulted a medical practitioner to confirm the relevance of the drug pairings for Scandinavian contexts, as well as to provide an additional, clinically non-significant pairing to allow testing of use cases with non-interacting drugs. Task 1 was to be performed with each of the drug pairings. Task 2 was performed with only the drugs from the first column (Drug X). Task 3 was performed using all drugs in combination, as well as using only Pair 6 for use case testing scenarios of no interaction. There were thus six variations for Tasks 1 and 2, and two variations for Task 3, adding up to 14 tasks. The pairings are presented in Table 2.

Table 2. Drug pairs applied in evaluated tasks.

\begin{tabular}{cll}
\hline \multicolumn{1}{c}{ Pair No. } & \multicolumn{1}{c}{ Drug X } & \multicolumn{1}{c}{ Drug Y } \\
\hline Pair 1: & Simvastatin & Itraconazole \\
Pair 2: & Warfarin & Gemfibrozil \\
Pair 3: & Levothyroxine & Warfarin \\
Pair 4: & Fluoxetine & Selegiline \\
Pair 5: & Selegiline & Phenelzine \\
Pair 6: & Cholecalciferol & Paracetamol \\
\hline
\end{tabular}

Although tailoring the set of heuristics applied is often recommended [27,28], we found the mHealth heuristics developed by Monkman and Kushniruk [24] too restrictive and specific for efficient application as mnemonic devices. We preferred instead the heuristics of Nielsen presented in Table 3.

Table 3. Nielsen's Usability Heuristics, based on Nielsen [23].

\begin{tabular}{cl}
\hline Identifier & \multicolumn{1}{c}{ Description } \\
\hline H1 & Visibility of System Status \\
H2 & Match Between System and the Real World \\
H3 & User Control and Freedom \\
H4 & Consistency and Standards \\
H5 & Error Prevention \\
H6 & Recognition Rather than Recall \\
H7 & Flexibility and Efficiency of Use \\
H8 & Aesthetic and Minimalist Design \\
H9 & Help Users Recognize, Diagnose, and Recover from Errors \\
H10 & Help and Documentation \\
\hline
\end{tabular}


The drug interaction checkers were evaluated independently by each evaluator in randomized order. The tasks were executed while inspecting the interface step by step. Evaluations were conducted using the personal smartphones of the evaluators, one of which was an iPhone XS, and the other an iPhone XR. One evaluator was using the native Safari browser, while the other used the Chrome browser. Durations of sessions were limited to a daily maximum of four hours to prevent results being affected by fatigue. Usability issues were recorded in a table, along with screenshots identifying the location of the issue. Severity ratings were given upon completion of all tasks for a given system, rather than issue-by-issue to contribute to coherent ratings. The scheme for severity ratings followed Nielsen [32], as described in Table 4.

Table 4. Scheme of severity rating applied, following Nielsen [32].

\begin{tabular}{cl}
\hline Rating & \multicolumn{1}{c}{ Description } \\
\hline 0 & $\begin{array}{l}\text { I don't agree that this is a usability problem at all. } \\
\text { Cosmetic problem only: need not be fixed unless } \\
\text { extra time is available. } \\
1\end{array}$ \\
2 & $\begin{array}{l}\text { Minor usability problem: fixing this should be given } \\
\text { low priority. } \\
\text { Major usability problem: important to fix, so should } \\
\text { be given high priority. } \\
\text { Usability catastrophe: imperative to fix this before } \\
\text { product can be released. }\end{array}$ \\
\hline
\end{tabular}

Upon having evaluated each system by each task, the evaluators independently reviewed the data across all systems to ensure consistency of records, mappings to heuristics, and severity ratings. By way of researcher triangulation, the evaluators then met over two sessions to discuss the issues identified to consolidate duplicates and to come to agreement on description, severity ratings and mappings to heuristics for each issue. An explicit evaluation protocol was shared between the evaluators to be kept at hand during evaluations in order to ensure uniform procedures. The evaluation protocol included the set of heuristics applied along with a short description of these as well as a table for recording usability issues according to predefined variables such as system name, task, description, applicable heuristics, screenshot, and severity assessment.

\subsection{Quantitative Analysis}

Initial analyses were performed using quantitative descriptive statistics for detection of patterns in the issue-based data. The analyses were based on the number of issues and their association to heuristics. We calculated the number and proportion of issues by severity rating for each system individually, as well as across all systems. The number and proportion of issues by heuristic applied was likewise calculated for single-case and cross-case analysis. Finally, the likelihood of an evaluator detecting an individual issue was calculated as a means of indicating the reliability of the findings. We used bar chart visualizations to facilitate identification of emergent patterns in the data.

\subsection{Qualitative Analysis}

The data were prepared through cleaning, coding, and sorting usability issues for qualitative analyses. We coded issues by reading through all issues pertaining to each system, before reviewing them again to categorize them according to the heuristic applied, as well as inductively by theme. Themes were finally revised and merged, if necessary. Emergent patterns were identified, and results were compiled as a narrative usability review for each system. Upon completion of single-case analyses, we performed cross-case analyses by reviewing the findings of all systems. This was done once for immersion and a second time for inductive coding and thematization. Categories were revised for merging and emergent patterns across systems were identified. As with single-case analyses, results were compiled as a cross-case narrative review. 


\section{Overview of the Drug Interaction Checkers}

The sampling of drug interaction checkers across the three Scandinavian countries of Denmark, Norway and Sweden produced a result of six eligible services. Interaktionsdatabasen.dk was found functionally identical to Medicinkombination.dk. To avoid redundancy in the evaluations, we included only Medicinkombination.dk, serving patient-oriented content. The resulting five drug interaction checkers are presented in Table 5.

Table 5. The drug interaction checkers sampled for the study.

\begin{tabular}{cl}
\hline Name & \multicolumn{1}{c}{ URL } \\
\hline Janusmed & https://janusmed.sll.se/ \\
Interaksjoner.no & https://www.interaksjoner.no/ \\
Felleskatalogen.no & https:/www.felleskatalogen.no/m/medisin/interaksjon \\
Legemiddelsok.no & https:/www.legemiddelsok.no/sider/Interaksjoner.aspx \\
Medicinkombination.dk & http://medicinkombination.dk/ \\
\hline
\end{tabular}

As seen below, we generated simplified sitemaps to visualize the site structure and association to internal and external resources. We also provide short summaries describing each service.

\subsection{Janusmed}

Janusmed is an integration of several knowledge and decision support systems provided by Region Stockholm. It is offered both as a version integrated with the Swedish electronic medical record system, and publicly as an online checker tool. The latter is associated with Janusinfo.se, the general drug information resource provided by Region Stockholm. Janusmed consists of a number of subsystems, four of which are integrated in the online checker: interactions, risk profile, effects on fetuses, and effects on breastfeeding. All subsystems are accessed through an integrated search interface. This interface provides result listings as a dynamic section of the page (Figure 2).

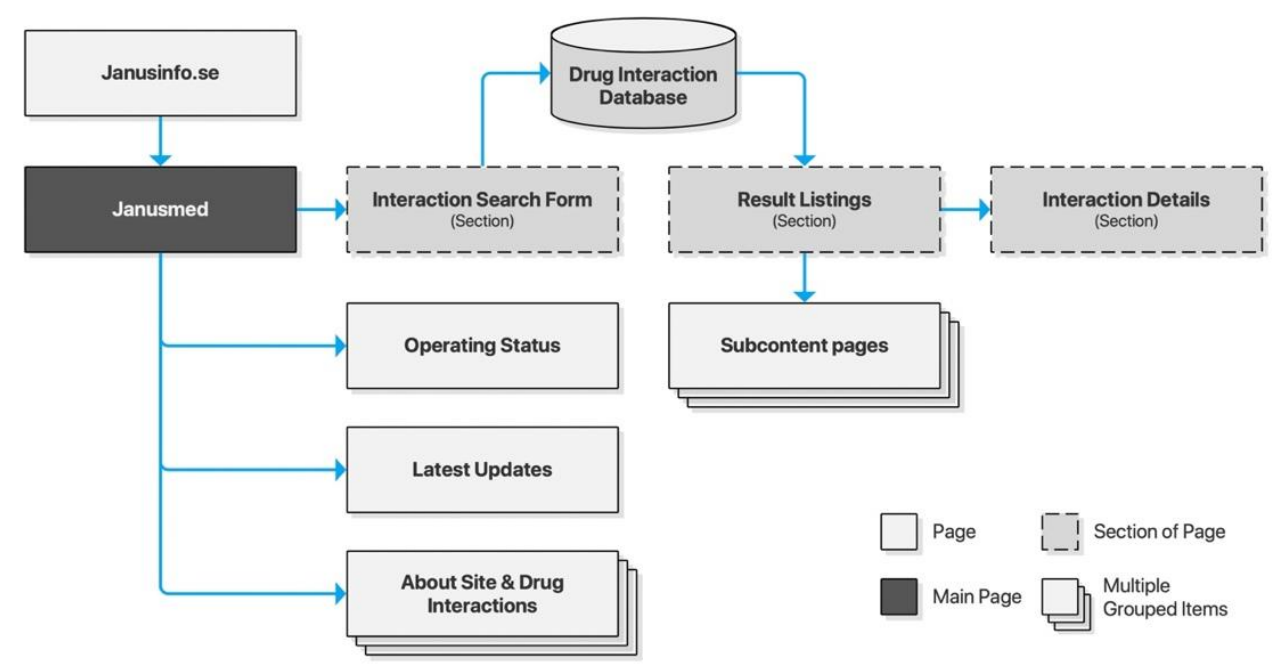

Figure 2. Sitemap for Janusinfo.se.

\subsection{Interaksjoner.no}

Interaksjoner.no was launched along with its Drug Information Database (DRUID) in 2000 through a collaboration of researchers from the University of Oslo, Trondheim Regional Hospital, and Pfizer AS. The database has since been acquired by the Norwegian Medicines Agency (NoMA) whose FEST (Forskrivnings- og ekspedisjonsstøtte) database Interaksjoner.no utilizes today. Interaksjoner.no is 
owned by DIPS AS, a private company specializing in eHealth applications for Norwegian hospitals and municipal healthcare providers. The drug interaction checker is a standalone website with a clear and minimalist interface providing users with a text input area and basic form controls. Results are listed on a separate page preserving the input form for iterative searches. Listings may be clicked for further details of each drug interaction (Figure 3).

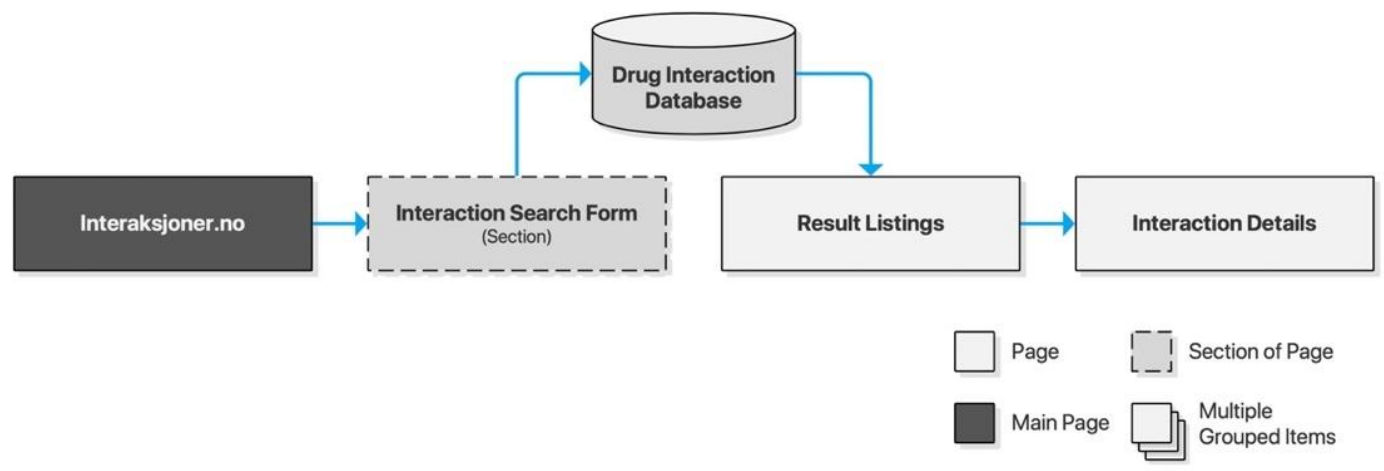

Figure 3. Sitemap for Interaksjoner.no.

\subsection{Felleskatalogen.no}

Felleskatalogen AS is a private company owned by the Association of the Pharmaceutical Industry in Norway. Felleskatalogen is a reference work published by Felleskatalogen AS, providing medical practitioners with comprehensive data on commercially available drug preparations in a handbook format, and is today primarily delivered free of charge online. The accompanying drug interaction checker is an integrated part of the website, accessible directly from the global navigation. Its content is based on NoMA's FEST database. Searches are performed through free text input supported by search suggestions. A selection of a search suggestion will populate a staging area on the page before submitting the query. Results are provided dynamically on the page, and drug interaction details are likewise expanded dynamically without traversing to new pages (Figure 4).

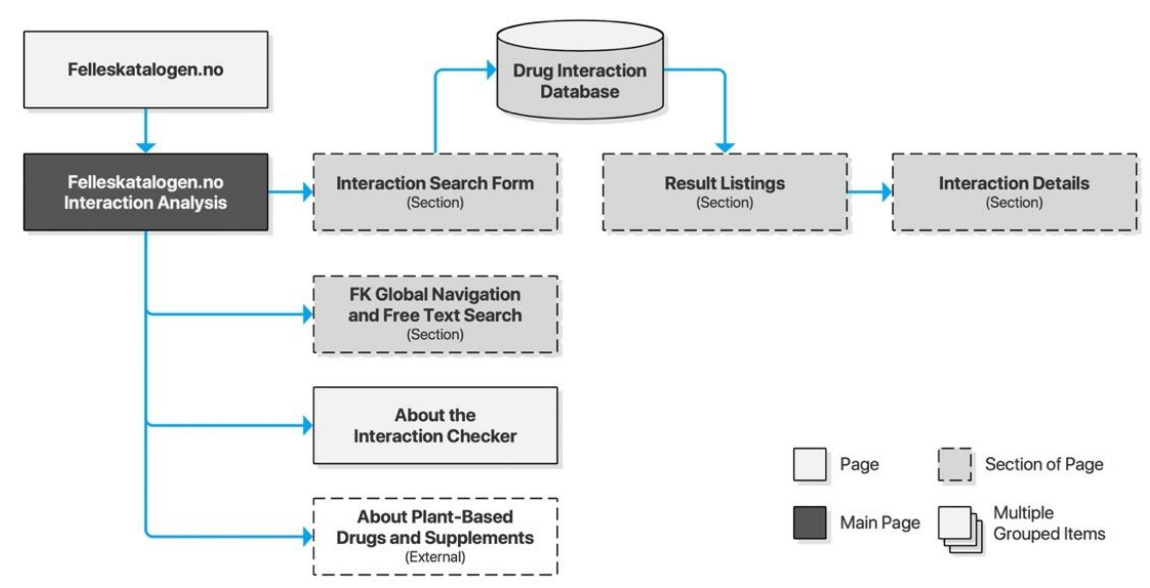

Figure 4. Sitemap for Felleskatalogen.no.

\subsection{Legemiddelsok.no}

The Norwegian Medicines Agency (NoMA) is the national regulatory authority supervising medicines for the Norwegian market. It is responsible for providing medical practitioners as well as the general public with necessary guidance for safe drug use. FEST is a drug information database maintained by NoMA, targeting medical practitioners and pharmacists. It informs them using comprehensive, quality-controlled, and continuously updated information about all prescription 
drugs on the Norwegian market. It is also integrated with electronic health record systems within the Norwegian general practitioner system, municipal healthcare, and some Norwegian hospitals. Access to the database is provided for third-party service providers, and the database provides the basis for Interaksjoner.no, Felleskatalogen.no, and Legemiddelsok.no.

Legemiddelsok.no is NoMA's own drug information system providing access to the FEST database. Drug interactions is a subsection of the site. Its search form consists of two free text input fields with controls for adding more fields, as well as submitting and resetting the form. Input fields are supported by search suggestions. Submitting the form will list results on a new page and listings may be clicked to retrieve detailed descriptions for each drug interaction on a new page. The search form is preserved throughout, allowing iterative searches (Figure 5).

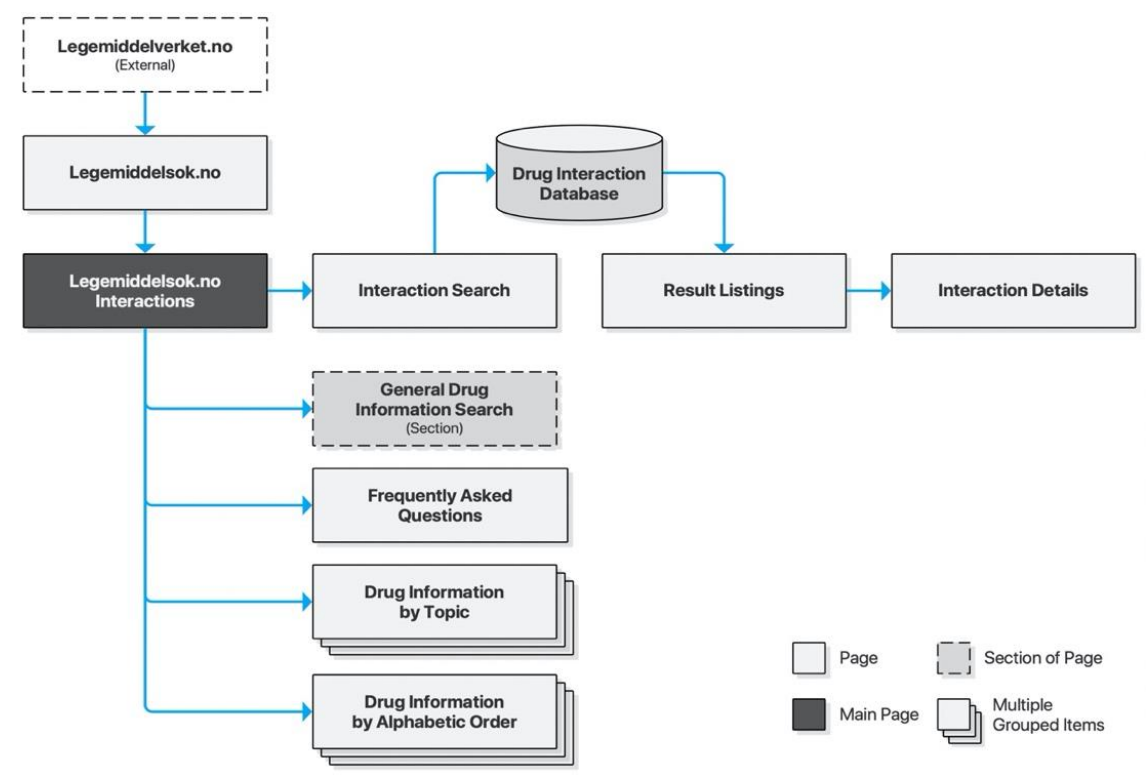

Figure 5. Sitemap for Legemiddelsok.no.

\subsection{Medicinkombination.dk}

The Danish Medicines Agency (DKMA) is Denmark's regulatory authority supervising medicines for the Danish market. Interaktionsdatabasen.dk is a drug information database developed in cooperation between the Association of Danish Pharmacies, the Danish Medical Association, Dansk Lægemiddel Information A/S, and the Danish Institute for Rational Pharmacotherapy. DKMA acquired the database in 2003. Access and documentation are provided for third-party integration, just like the Norwegian FEST database. In 2007, Medicinkombination.dk was launched as a sister site to Interaktionsdatabasen.dk, with a separate content database targeting laypeople. Its search interface is separated into two search forms: one for single-drug searches and another for multi-drug searches. Both lead to a new page for result listings, which again leads to a new page for detailed descriptions. As opposed to the other checkers described above, the search form is not preserved across pages, requiring users to traverse the browser history for new searches (Figure 6). 


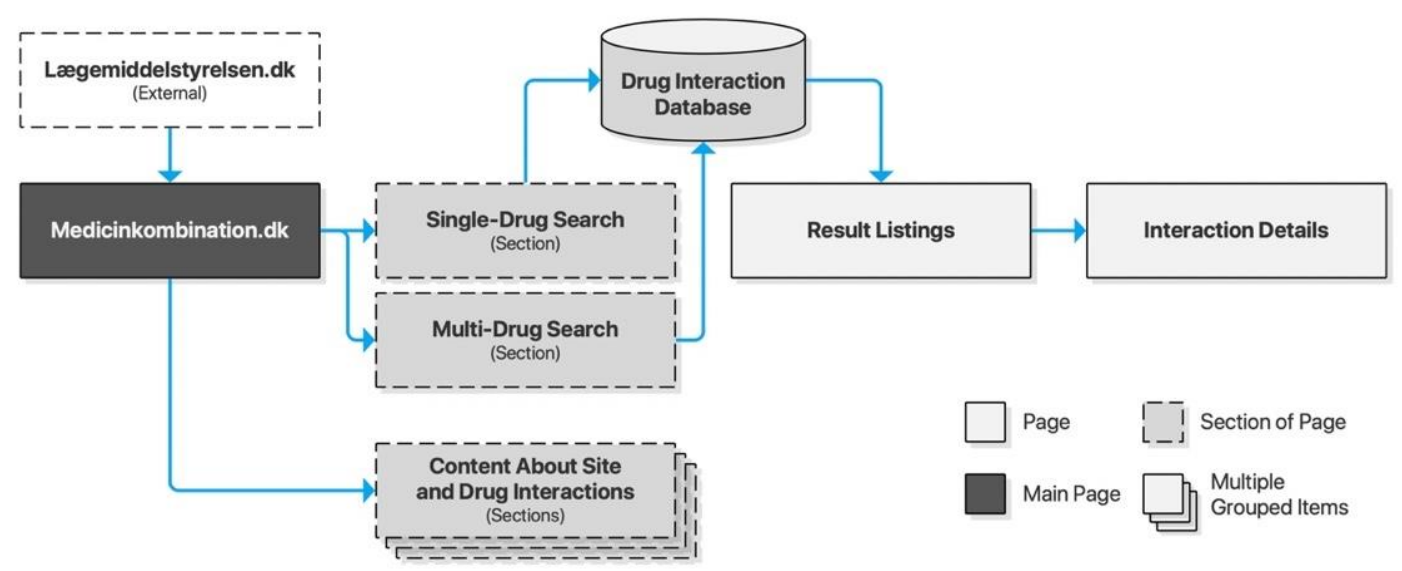

Figure 6. Sitemap for Medicinkombination.dk.

\section{Results}

This section presents empirical findings and analyses. Quantitative and qualitative analyses are applied to the usability issues identified by the heuristic evaluations. Descriptive statistics are applied to identify patterns in the data. Qualitative single-case and cross-case analyses are then applied to explore emergent patterns at depth. The full set of usability issues is available in Appendix A.

\subsection{Quantitative Analysis}

Having accounted for drug interaction checkers available to the Scandinavian public, we applied descriptive statistical analysis to identify patterns in the issue-based data. The analysis revealed a total of 165 usability issues across all checkers. The majority of these were minor issues, but many were also classified as major. Three were even assessed as catastrophic due to their potential for harm to human health. In total, we found 25 cosmetic, 114 minor, 23 major, and 3 catastrophic issues. Looking across services, shows Janusmed having about twice the mean number of usability issues. Interaksjoner.no was, on the other hand, found to have only half the mean number of issues. The remainders were closely distributed around the mean (Figure 7).

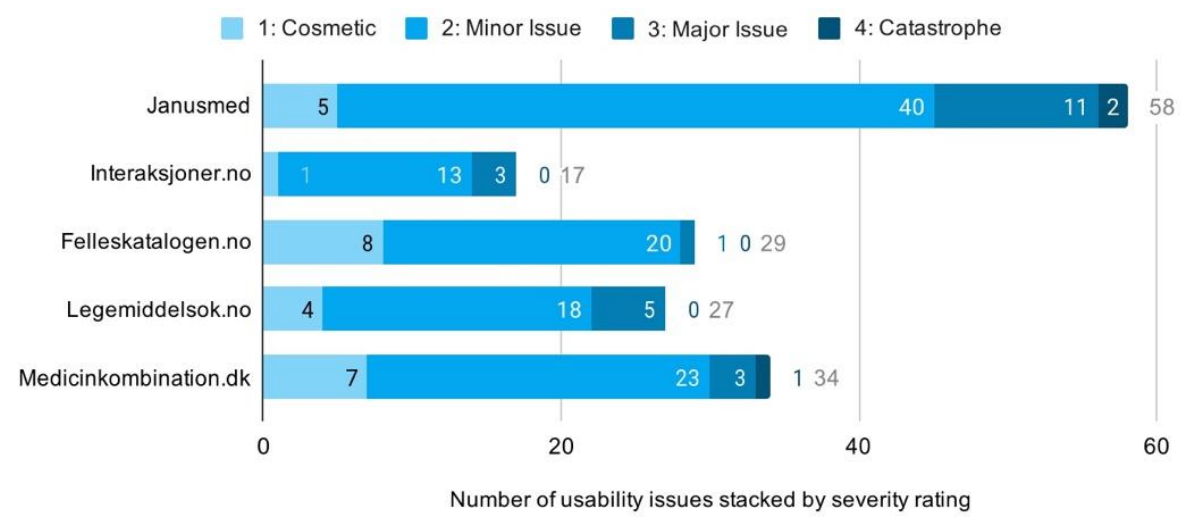

Figure 7. Distribution of usability issues across services.

The proportion of issues by severity rating shows high consistency across the checkers. Minor issues make up the majority of issues, with most services clustering closely from $67 \%$ to $69 \%$. Felleskatalogen.no is the primary exception with very few major issues. Its distribution of issues is even shifted all the way to cosmetic, rather than minor issues, making for notably lower overall severity ratings (Figure 8). 


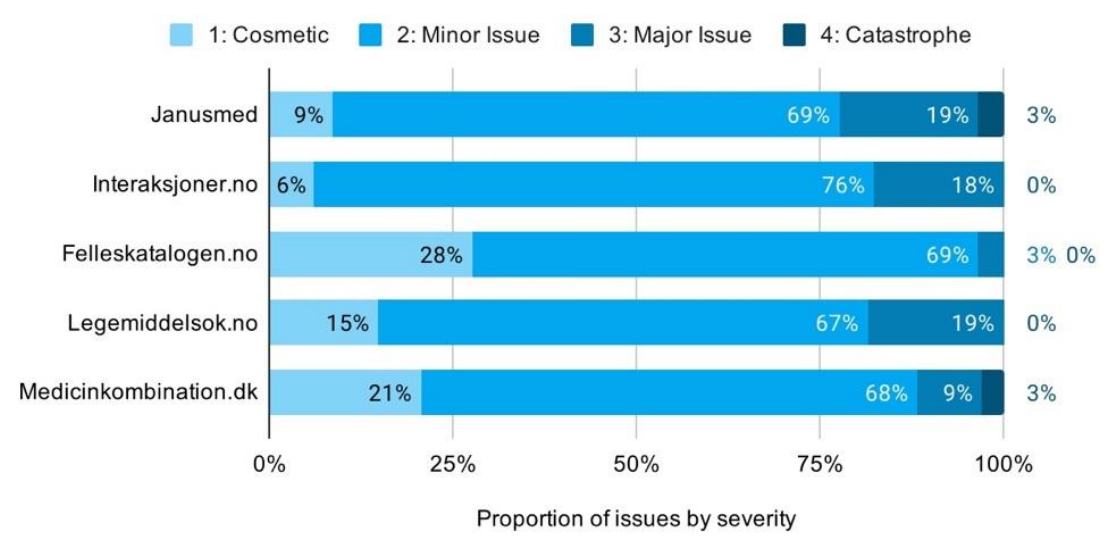

Figure 8. Proportion of usability issues by severity across services.

As for the characteristics of the issues identified, an overview of the total distribution of issues by heuristic reveals that flexibility and efficiency of use (H7), consistency and standards (H4), aesthetic and minimalist design (H8), match between system and the real world (H2), and user control and freedom (H3) represent the most frequent sources of usability issues (Figure 9).

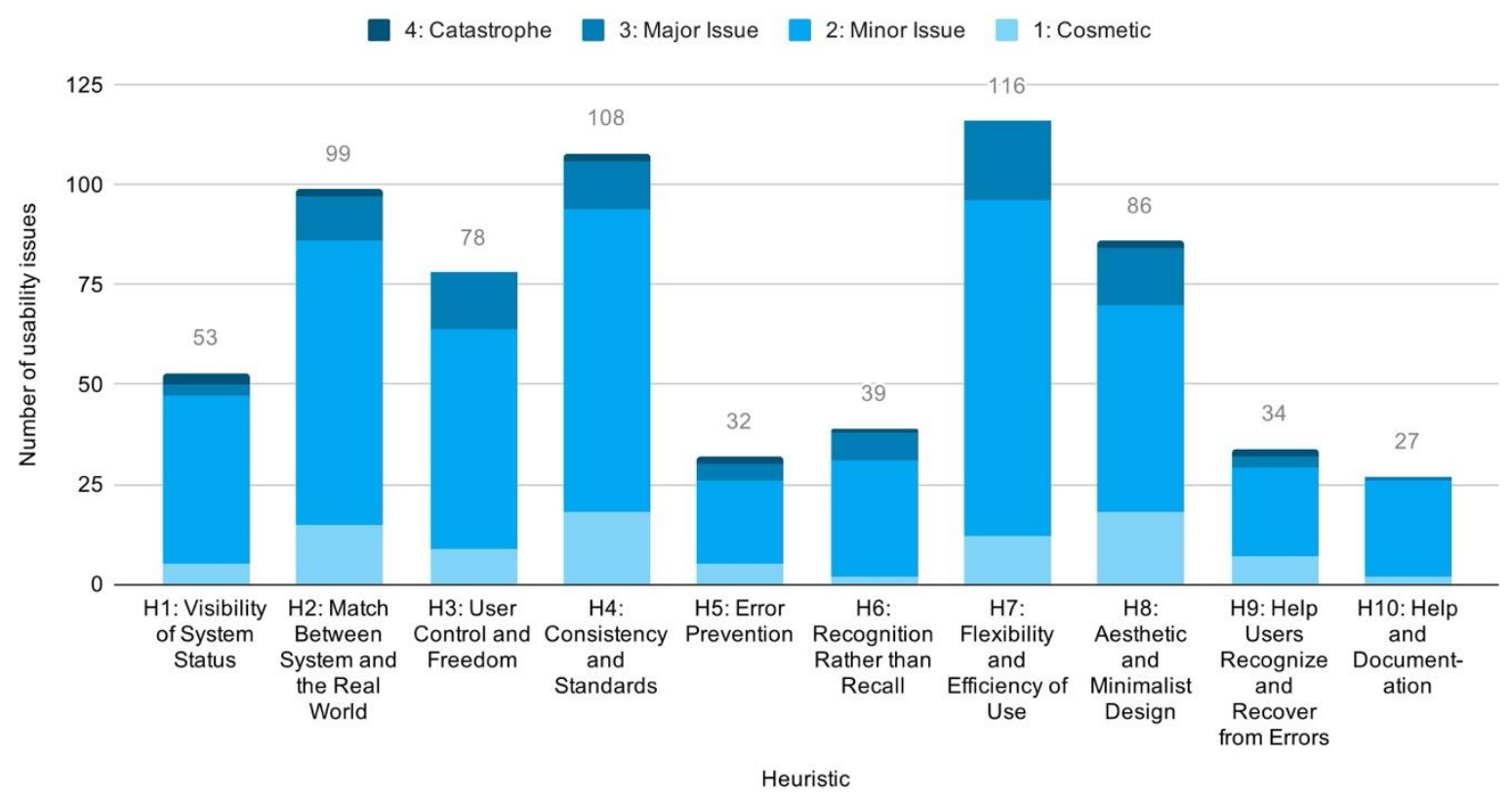

Figure 9. Distribution of issues by heuristic.

Dividing these statistics by checkers, generally shows high consistency. Interaksjoner.no had fewer issues related to consistency and standards (H4) and aesthetic and minimalist design (H8), but more issues related to flexibility and efficiency of use (H7). Janusmed, Legemiddelsok.no, and Medicinkombination.dk had more issues with consistency and standards (H4) and aesthetic and minimalist design (H8). These results are exhibited in Figure 10 on the next page. 


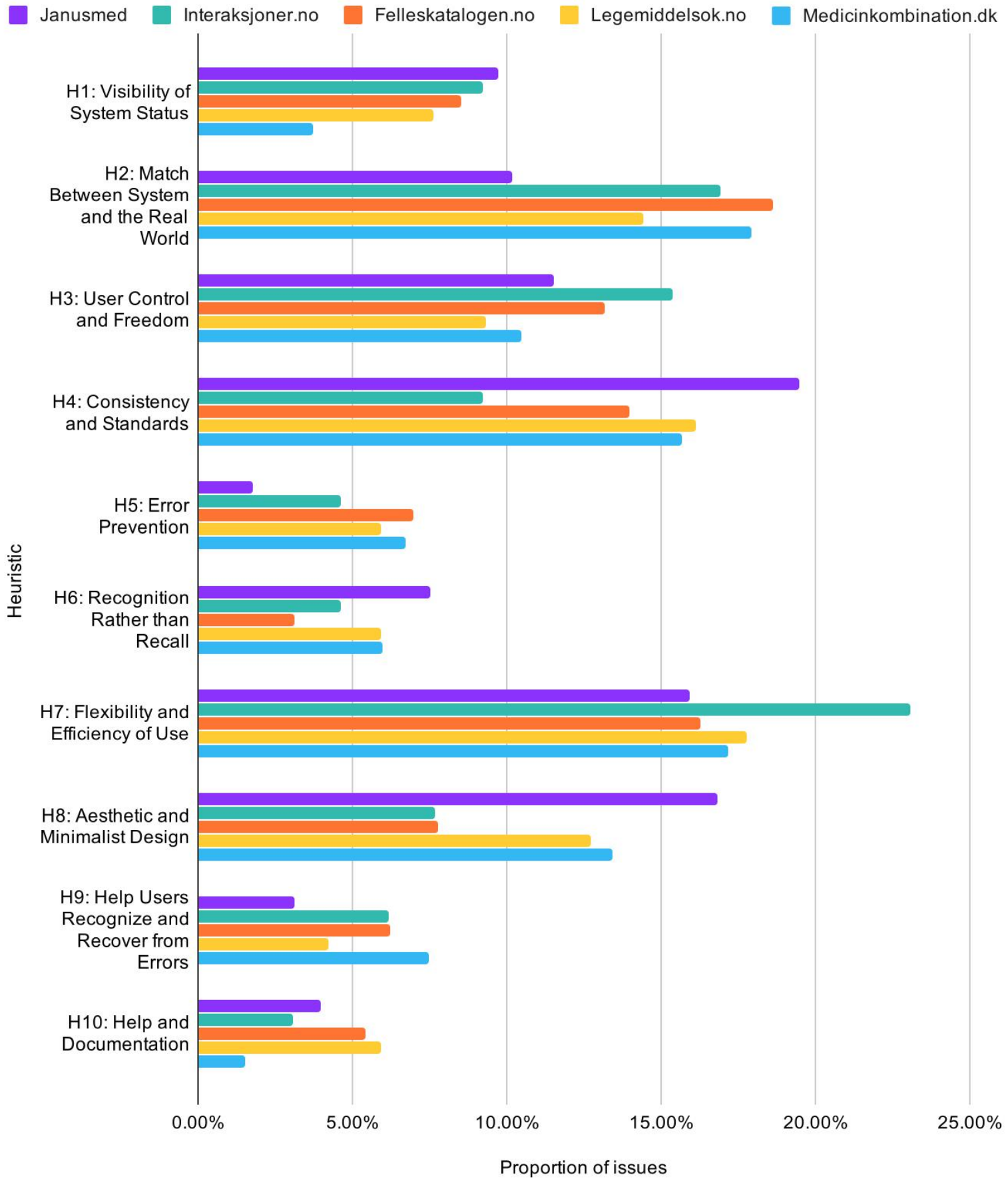

Figure 10. Proportion of usability issues by heuristic across services.

\subsection{Cross-Case Qualitative Analysis}

Qualitative analyses identified four major themes across the drug interaction checkers: lack of adaptive design, lack of patient-oriented content, system complexity correlating with the amount of usability issues, and a lack of following conventions, design principles and patterns.

\subsubsection{Lack of Adaptive Design}

The layouts and interfaces of the majority of the checkers did not adapt to different screen sizes. Only Interaksjoner.no and Felleskatalogen.no had well-functioning adaptive layouts. Legemiddelsok.no and Medicinkombination.dk both made no effort to accommodate mobile usage of their services. This neglect resulted in major issues related to efficiency and ease of use, as well as 
aesthetic design. Janusmed was a particular case as it did in fact have an adaptive design yet still failed to avoid typical issues of non-adaptive designs, such as forcing viewport management.

\subsubsection{Lack of Patient-Oriented Content}

Of all the drug interaction checkers evaluated, only Medicinkombination.dk had content clearly aimed at patient audiences. All the Norwegian checkers retrieved interaction data from the same FEST database, but presented it somewhat differently in terms of order and priority. We found its content appropriate in extent and complexity, but frequently using acronyms and technical terms detrimental to patient accessibility. The content of Janusmed was found to be both too extensive and too technical for patient audiences, as well as too reliant on acronyms and technical terms. As for Medicinkombination.dk, we found its content accessible but of limited extent.

\subsubsection{More System Complexity Correlating with More Usability Issues}

We identified a positive correlation between system complexity and the number of usability issues detected. We found Janusmed, in particular, very complex in terms of organization, content, layout, typography and patterns of interaction. Interaksjoner.no, on the contrary, had simplistic interaction, limited functionality, and minimalist layout and typography. Usability issues for Janusmed and Interaksjoner.no correspondingly numbered 58 and 17, respectively. The other three checkers were found comparatively moderate in both complexity and number of usability issues (Figure 7 above).

\subsubsection{Lack of Adherence to Conventions, Design Principles and Patterns}

The final theme was a general lack of adherence to recognized design conventions and principles across all the drug interaction checkers. A successful basic pattern of interaction appeared well established across the checkers, but specific implementations would vary and err on basics. Examples were issues such as insufficient type sizes and touch target areas, using low-contrast grey for highlighting selection, or failing to clarify relations between content and functionality through visual hierarchy and gestalt principles.

\subsection{Single-Case Qualitative Analyses}

Having provided descriptive statistics and cross-case qualitative analysis, we lay out here emergent themes for each individual drug interaction checker through single-case qualitative analyses.

\subsubsection{Janusmed}

Janusmed distinguished itself by applying a particularly advanced interaction pattern for its search form, and by putting direct manipulation to good use. Completed and recognized search terms were instantly transformed to visual objects that could be removed item by item without text editing or handling multiple input fields. Feedback was also immediate and in place, rather than keeping users waiting or allowing them to complete invalid queries. Perplexingly, this was accompanied by several catastrophic usability issues, as well as a severe lack of adherence to basic design principles such as gestalt principles, visual and typographic hierarchy, affordances of pliability, coherent interaction idioms, and regard for users' mental models.

A pertinent example is how subsections are independently nested under the unified checker for display one section at a time, much as module tabs would be. The sections are controlled not by tabs however, but by unconventional button-displays, in a two-by-two orientation without gestalt principles indicating their association with the content (Figure 11a). Adding another layer of complexity, local submenus are provided within the subsections of the checker. The menu items of these submenus inconsistently direct to internal or external links loaded sometimes in new browser tabs and sometimes as dynamic content within the subsection. Content in new tabs generally comes without any means of navigation (Figure 11b). 


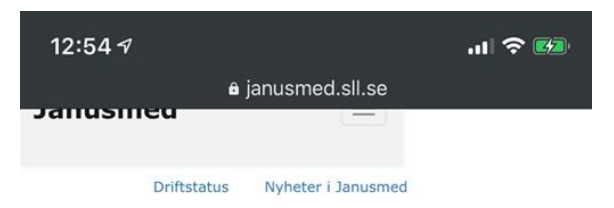

Sök på läkemedelsprodukt

och/eller substans
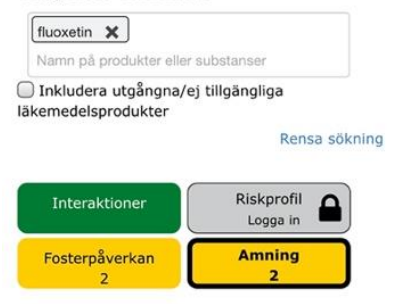

Startsida amning Aktuellt

Klassificering För allmänheten

Amning

Janusmed amning tillhandahåller generella

rekommendationer om huruvida ett friskt

fullgånget spädbarn kan am
använder olika läkemedel.
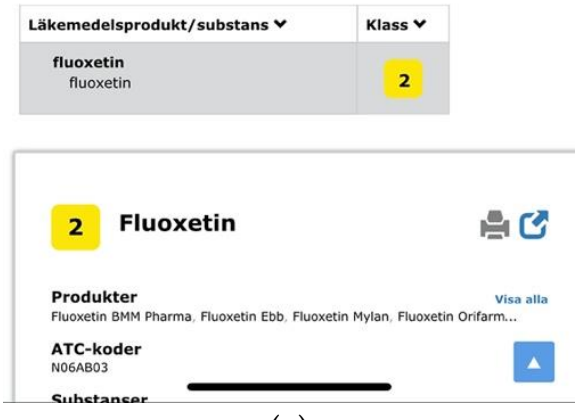

(a)
$12: 56 \triangleleft$ $.11 \%$<smiles></smiles>

Aktuellt om Janusmed amning

Länkar till information om covid-

19 och amning

- SFOG. Rekommendation om

handläggning av barn till kvinnor med

verifierad/sannolik Covid-19.

- CDC. Information about Coronavirus

Disease 2019 - Breastfeeding.

- RCOG. Coronavirus (COVID-19)

Infection in Pregnancy. Information

for healthcare professionals.

- WHO. Q\&A on COVID-19,

pregnancy, childbirth and

breastfeeding.

2020-03-24

Bidra till EU-tjänst om läkemedel

vid graviditet och amning

2020-02-04

Statiner, triptaner och hostmedel

Texterna om statiner (ATC-kod

C10AA), triptaner (N02CC) och

hostmedel (R05C) har uppdaterats.

2019-11-19

Antikonceptionella medel och

bensodiazepiner

Nu är alla texter om

(b)

Figure 11. (a) Visual and typographic hierarchies at Janusmed are broken across sections of the page;

(b) Current news for the breastfeeding section opens in a new tab without means of navigation.

Another particularly vexing example was that placing focus in the input field would zoom and drag the user's viewport, which would hide instructions and controls. Focus would be triggered by touching any of the label, input field, or even the checkbox below. This corresponds to about 20-25\% of the screen real estate. Focus would trigger even upon initiating touchstart, for example when starting to scroll the page over any of these elements. This combination of both complexity and lack of adherence to design principles explains the large amount of usability issues identified-twice the mean of all checkers evaluated. It also explains the prevalence of issues related to consistency and standards and aesthetic design, in spite of an ostensibly adaptive layout. It also contributes in explaining the relatively high severity ratings given.

\subsubsection{Interaksjoner.no}

Interaksjoner.no displayed the opposite trends of those of Janusmed. Taking a minimalist approach, its interface was adaptive as well as exceedingly clear in terms of visual and typographic hierarchy. Its interaction idioms were likewise simple, coherent and conventional, based on a basic page-by-page interaction (Figure 12a,b). This provided excellent basic usability. 


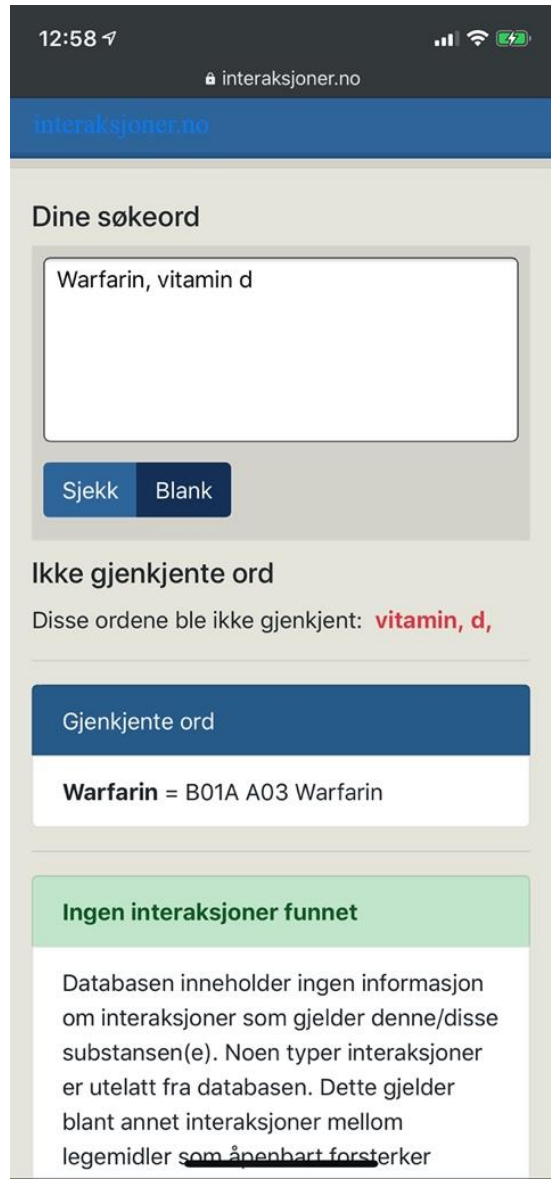

(a)

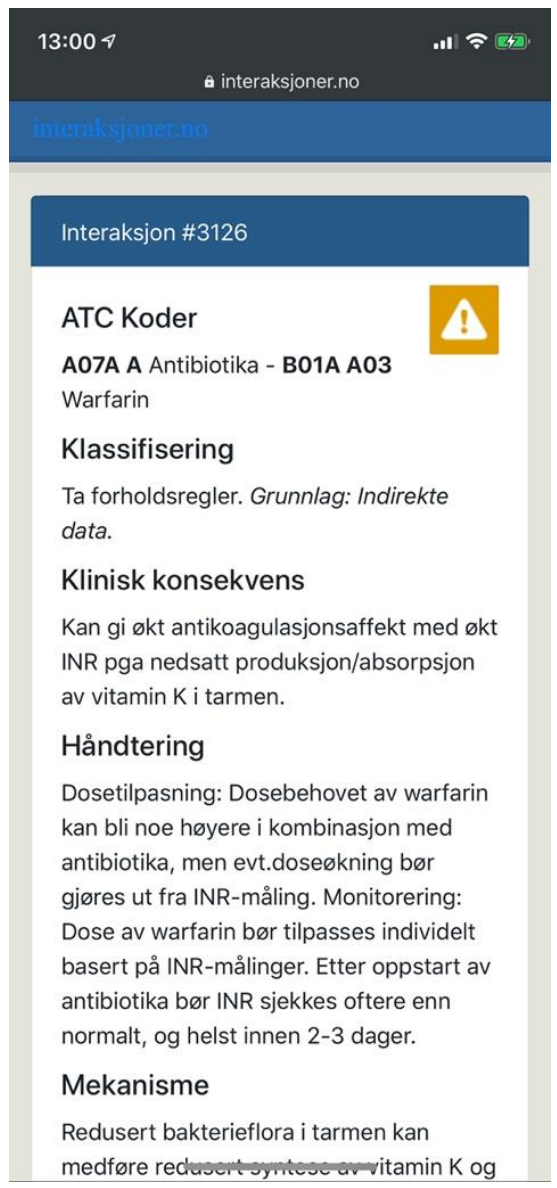

(b)

Figure 12. (a) Interaksjoner.no with an adaptive layout, a clear visual hierarchy and clear feedback; (b) Drug interaction details open on a new page in the same browser tab.

Interaksjoner.no failed, however, to provide users with necessary means of support. The task of entering long and complex names of drug substances is demanding and error-prone. At the same time, searches on Interaksjoner.no were performed by free text entry only, providing no search suggestions or other means of help. Users were expected to provide exact input, and were expected to do so according

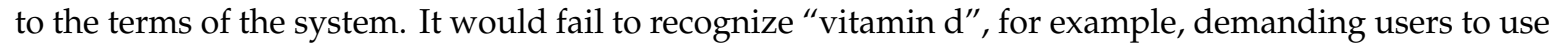
underscores instead of spaces. It would also fail to recognize "vitamin" or " $\mathrm{d}$ " individually, or offer a thesaurus or similar functionality (Figure 12a).

As such, Interaksjoner.no and Janusmed provided contrasting examples; one excelling at the basics but failing to deliver necessary support; the other offering advanced means of support but failing to deliver it according to basic principles of design. This reflects findings from descriptive statistics showing Interaksjoner.no having fewer issues due to its minimalist design and success at basic usability. It is also reflected by a larger proportion of major usability issues stemming precisely from lack of user support.

\subsubsection{Felleskatalogen.no}

Felleskatalogen.no and Interaksjoner.no were the only checkers evaluated that provided a well-functioning adaptive layout (Figure 13a). This resulted in fewer and less severe usability issues. The clarity and visual hierarchy of Felleskatalogen.no was not as strong as that of Interaksjoner.no, but sufficient to avoid more severe issues. 


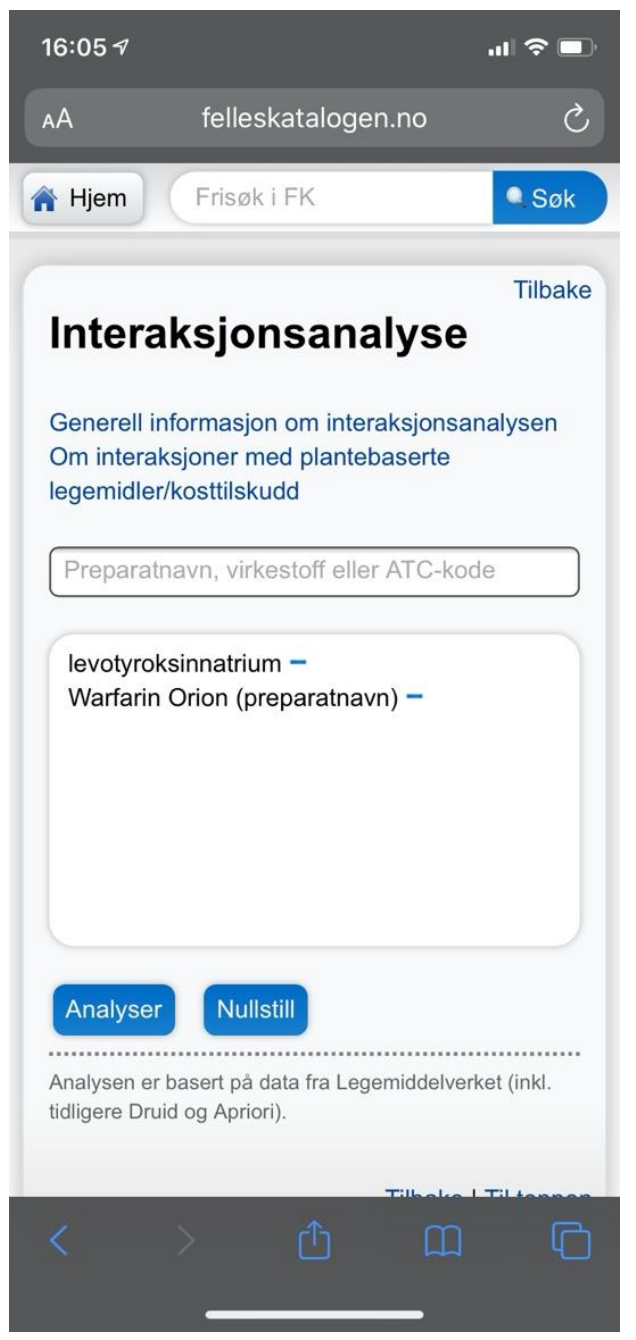

(a)

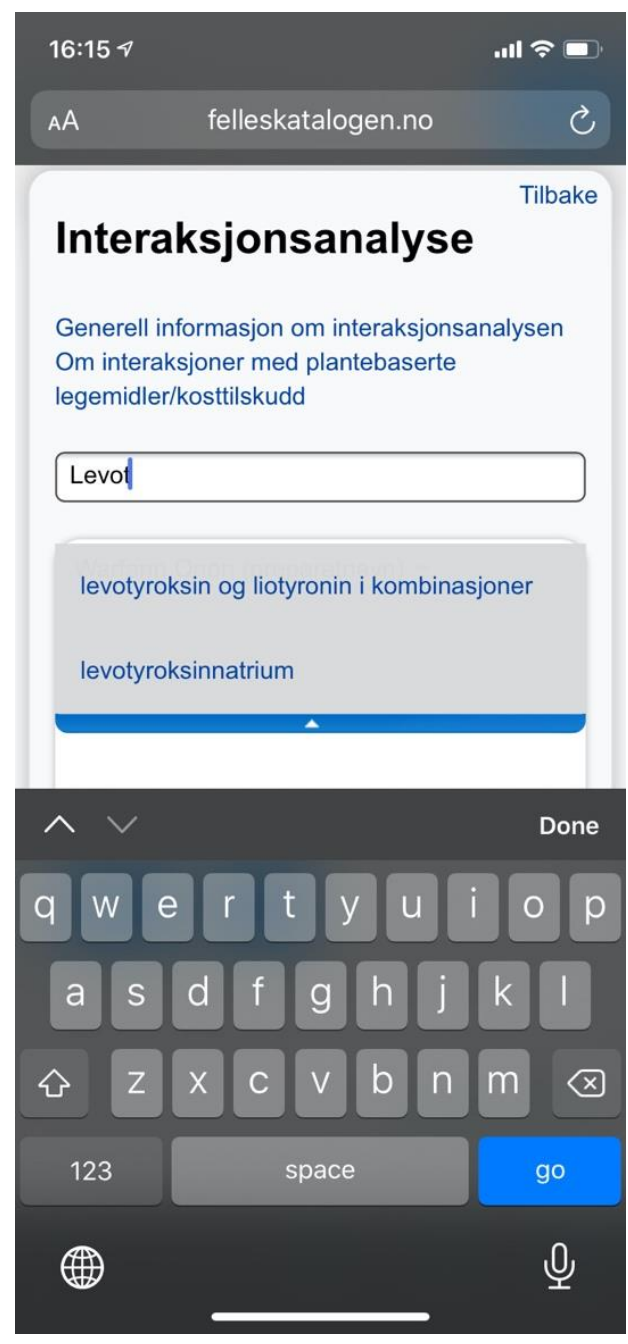

(b)

Figure 13. (a) Felleskatalogen.no providing a mobile adaptive layout avoiding issues with zoom and viewport handling; (b) Felleskatalogen.no did provide search suggestions to help users choose the appropriate search terms.

Felleskatalogen.no did, however, offer search suggestions (Figure 13b), avoiding much of the critique concerning lack of user support. The result was a comparatively small proportion of major usability issues as indicated also by the quantitative analyses (Figure 8). Quantitative analyses showed that the number of issues was nevertheless close to the mean, and not nearly as low as that of Interaksjoner.no. This reflects the pattern of correlation between the number of usability issues and the complexity of the system, as identified by the cross-case analysis.

\subsubsection{Legemiddelsok.no}

Legemiddelsok.no showed a complete lack of adaptive design, utilizing a particularly horizontal layout that necessitated considerable viewport management on mobile devices (Figure 14a). This was reflected in quantitative analyses showing particular prevalence of issues with aesthetic and minimalist design, and consistency and standards (Figure 10). Legemiddelsok.no also had a notable lack of basic instructions and documentation. "Search tips" were hidden behind a vague icon, which would arbitrarily load its content in a modal panel. This modal panel would stick outside of the user's viewport on mobile devices due to a lack of adaptive design (Figure 14b). 


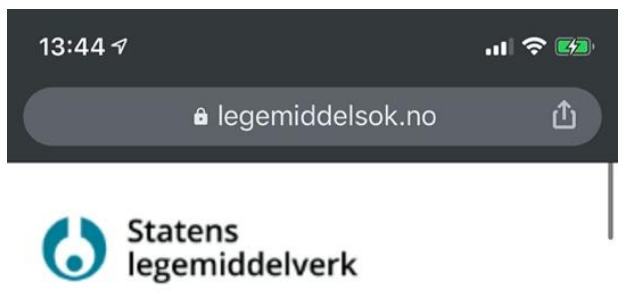

Interaksjonssøk

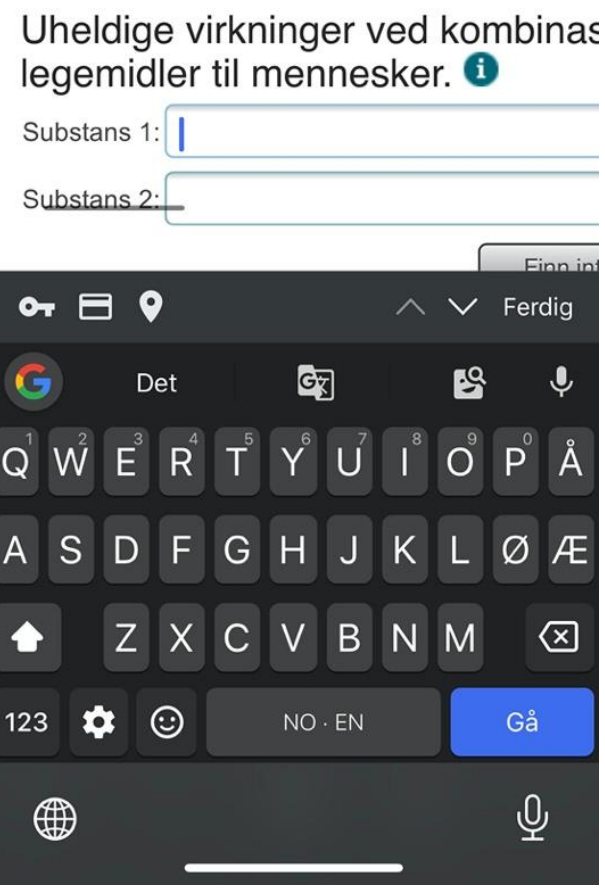

(a)

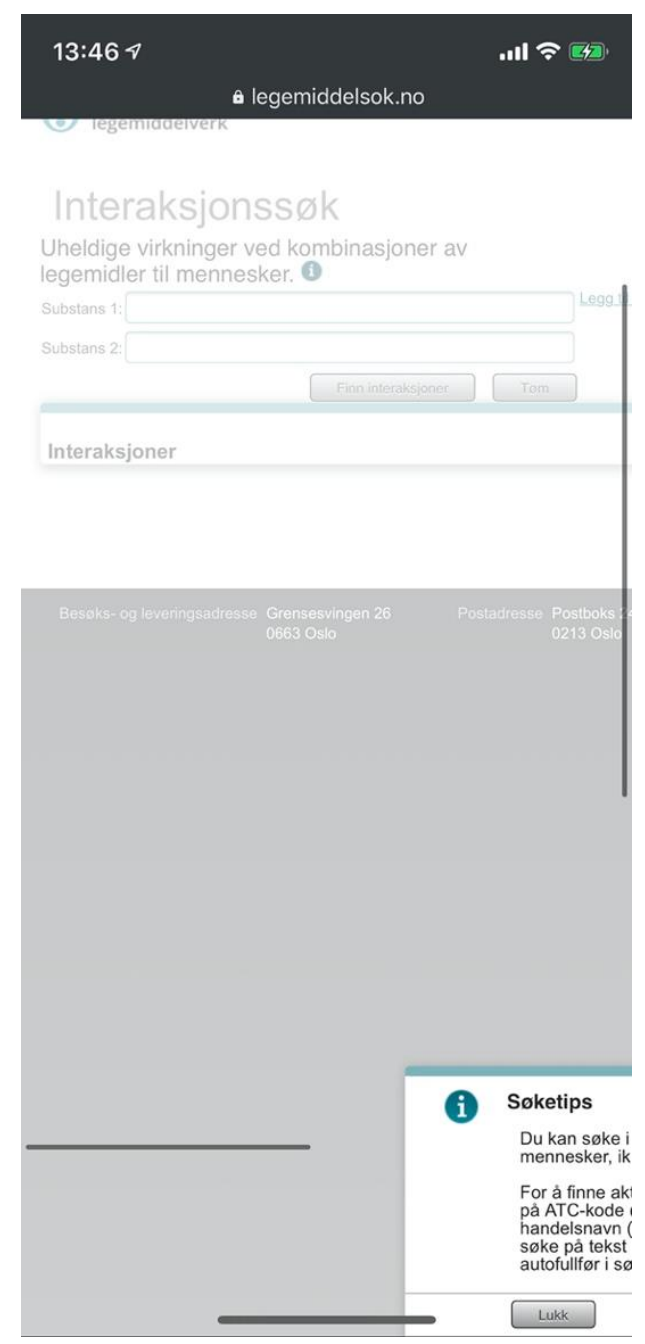

(b)

Figure 14. (a) Issues of viewport handling prevent usability at Legemiddelsok.no, and no welcoming instructions are provided; (b) "Search tips" modal panel sticking outside the viewport.

Comparing Legemiddelsok.no to other drug interaction checkers showed an average amount of issues, and a similar proportion of major issues compared to that of Janusmed and Interaksjoner.no-considerably larger than that of Felleskatalogen.no.

\subsubsection{Medicinkombination. $\mathrm{dk}$}

Medicinkombination.dk distinguished itself by offering patient-oriented content explicitly targeting layperson audiences. It, unfortunately made no effort to accommodate mobile devices (Figure 15a). This offers a partial explanation for the prevalence of issues related to consistency and standards and aesthetic and minimalist design. 


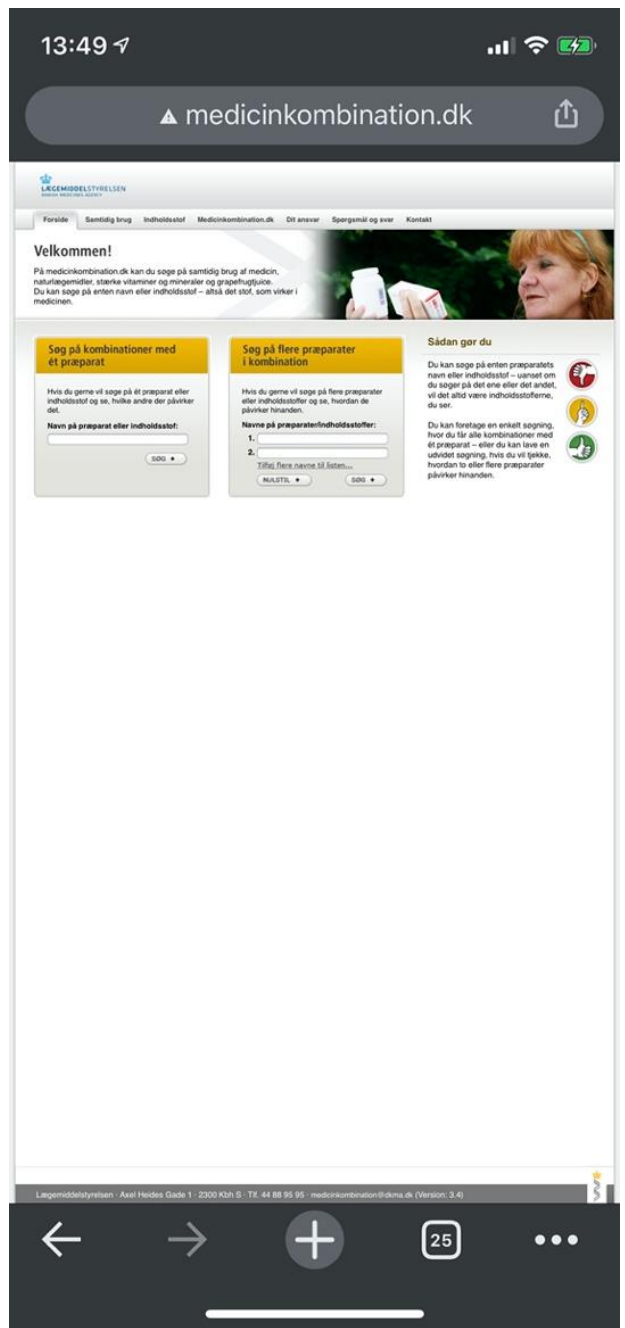

(a)
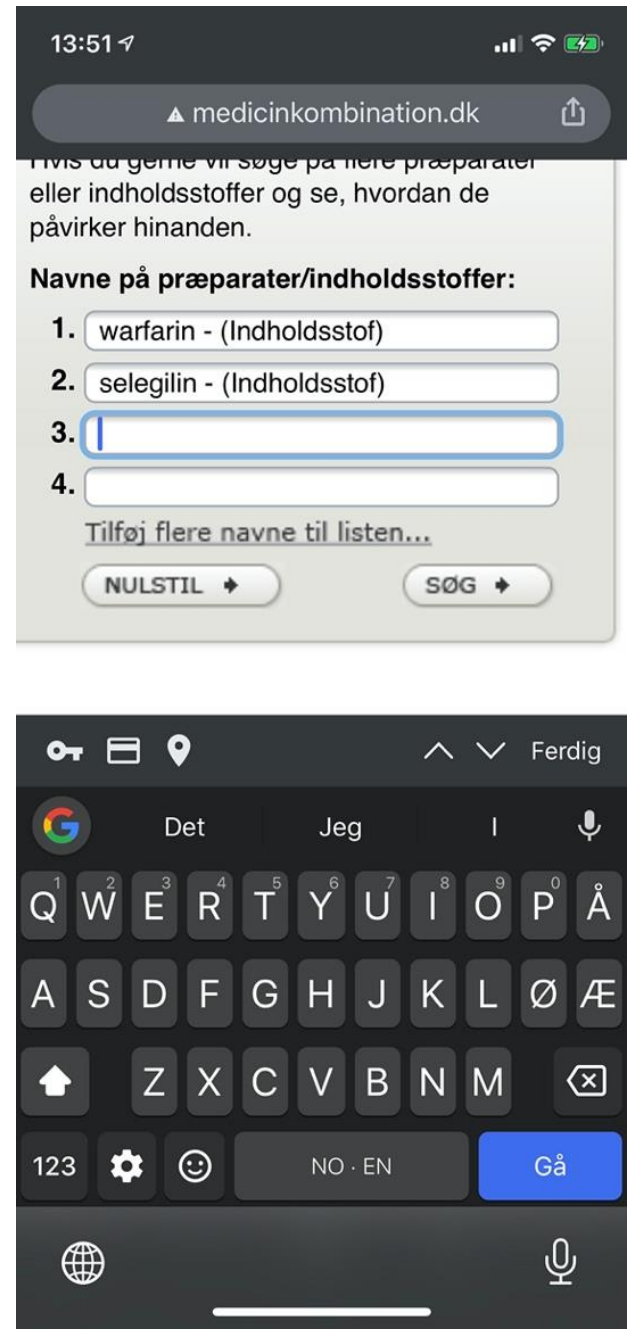

(b)

Figure 15. (a) Medicinkombination.dk lacking adaptive design in spite of an explicit layperson audience; (b) Multi-drug searches require users to manually add input fields one by one.

Medicinkombination.dk was found to contain a catastrophic issue potentially leading users to the impression that harmful drug pairings were in fact safe. Apart from this defect, Medicinkombination.dk leaned more towards Felleskatalogen.no in displaying a smaller proportion of major issues than other checkers, compensating with cosmetic rather than minor issues. This made for comparatively low overall severity ratings. It was the only checker to provide two separate interfaces for single-drug and multi-drug searches. Multi-drug searches, moreover, required users to add new input fields one by one (Figure 15b). The approaches of Felleskatalogen.no and Janusmed were considerably more efficient, allowing users to enter any number of drugs through a unified and coherent interface.

\subsection{Catastrophic Usability Issues}

Beyond the cross-sectional themes, we also identified three catastrophic usability issues. Entering a single drug substance on Janusmed would invariably yield positive feedback through green color coding indicating that the drug would be safe from interactions with other drugs, whereas the opposite might in fact be the case (Figure 16a). The lack of emphasis and labelling on the indicator for interactions pertaining to single drug items was the second issue related to the same scenario. This would fail to notify users of hundreds of potentially serious interactions (Figure 16b). 


\section{Sök på läkemedelsprodukt och/eller substans}

warfarin $x$
Namn på produkter eller substanser
Inkludera utgångna/ej tillgängliga
läkemedelsprodukter

Rensa Sı

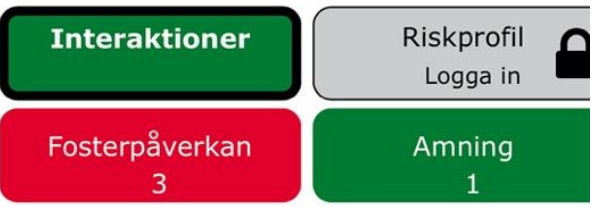

(a)

\section{Interaktioner}

Tjänsten ger en generell information utifrån substansens egenskaper och administrationsväg och tar inte hänsyn till patientens ålder, kön eller aktuell dosering.

Visa A-interaktioner

warfarin (345)

Janusmed interaktioner produceras i samarbete mellan

Klinisk farmakologi, Karolinska Universitetssjukhuset och

Hälso- och sjukvårdsförvaltningen, Region Stockholm.

Interaktionsinformationen senast uppdaterad 2020-09-02

\section{(b)}

Figure 16. (a) A green indicator for interaction analysis of warfarin indicating its safety; (b) Visually de-emphasized and unlabeled indicator for 347 drug interactions pertaining to warfarin.

These issues showed a lack of regard for users' mental models, answering not the question "What interactions pertain to this drug?" but rather "What interactions pertain to this drug and nothing else?" Other drug interaction checkers simply listed all relevant interactions also for single-drug searches.

The third catastrophic issue pertained to Medicinkombination.dk (Figure 17). Its multi-drug search form would fail to catch cases of non-recognized search terms, and would instead present results from previous searches. Unobservant users would not expect any error had occurred and might easily ignore indications that the result displayed was not for the query entered. Users could first search for a harmless drug pairing to retrieve a confirmation of its safety. Following searches containing misspellings would then present the same confirmation of safety even if the intended pairing might cause serious interactions (Figure 12). We deemed this a flaw of implementation rather than design, as opposed to those observed on Janusmed.

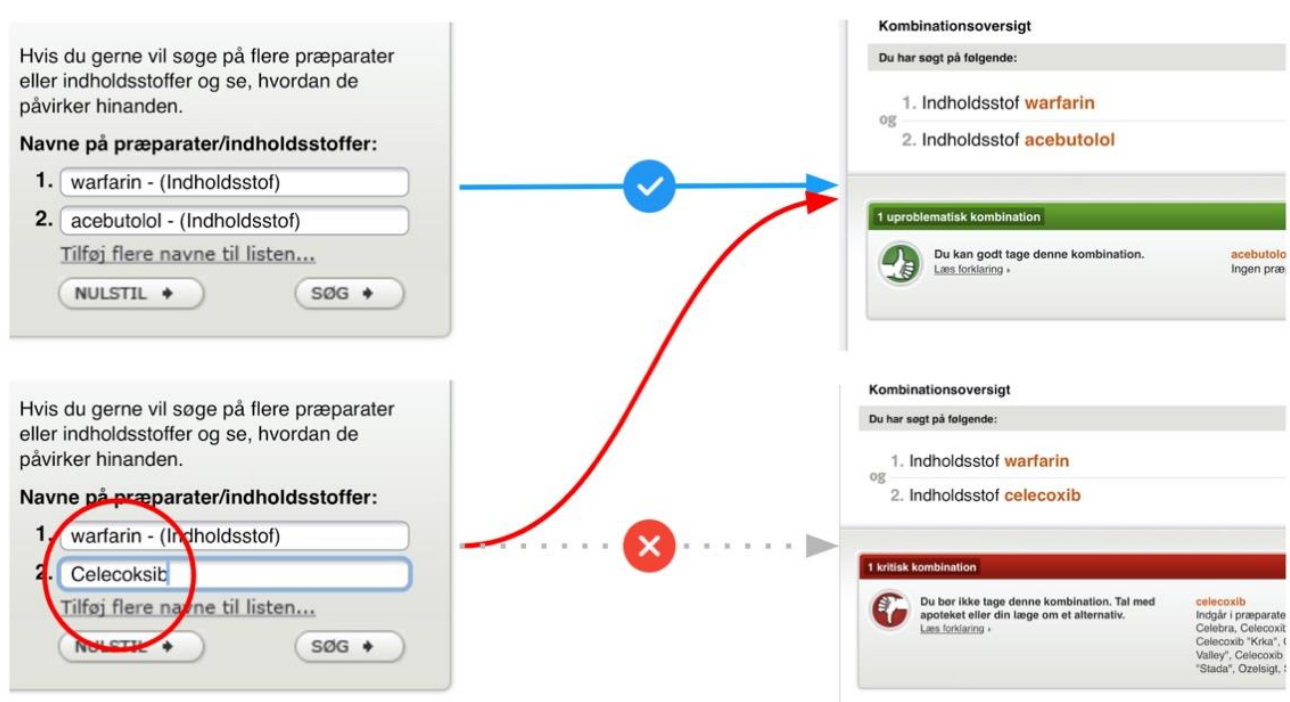

Figure 17. Medicinkombination.dk providing previous results for a current search.

All of the noted catastrophic usability issues were deemed catastrophic due to their potential to lead to harm to human health. 


\section{Discussion}

Allowing patients to act as decision-makers regarding their own health requires empowering them with information. The systems conveying this information must be usable in order for empowerment to take place. In this paper, we identified six drug interaction checkers publicly available to Scandinavian audiences: three in Norway, two in Denmark, and one in Sweden. The Norwegian checkers all utilized the same professionally oriented database. The two Danish checkers, on the other hand, utilized the same interface to serve content from different databases-one professionally oriented and one patient-oriented. The Swedish checker served only professionally oriented content and did so using multiple topically oriented databases. The service providers were national authorities, drug industry associations and private eHealth businesses. All of them served content from national authoritative sources, however. All except one of the checkers primarily targeted professional audiences as a means of clinical decision support, while at the same time allowing public access. Only Medicinkombination.dk targeted patient audiences with highly readable patient-oriented content. This constitutes an important contribution to patient-oriented healthcare in Denmark.

Although this paper has not aimed to investigate content specifically, it was noted that checkers targeting professional audiences did so frequently using acronyms and technical terminology. Acronyms are particularly difficult for laypersons to interpret as web searches for their meaning will often yield incorrect or poorly targeted results. Content will consequently not only be hard to read, but sometimes even inaccessible. As Nörby et al. [12] have shown, this does not stop patients from using these checkers, but is suggested to cause anxiety for some users. It also prevents the benefits of empowering and engaging patients in regard to their health.

The heuristic evaluations showed all of the checkers applying patterns of progressive disclosure, from summarized listings of drug interactions to detailed descriptions and even external links for further reading. This might seem an appropriate pattern to preserve in order to accommodate patients' varying attitudes towards supplementary drug information, as identified by Kusch, Haefeli and Seidling [8]. Although the content of Medicinkombination.dk was very readable, it was also very brief. This may represent a precautious approach to provide content without causing anxiety. It may, however, also limit the positive effects of improved communication with professionals and improved compliance, as suggested by Nörby et al. [12].

\subsection{Prevalence and Characteristics of Usability Issues}

In terms of usability issues and their characteristics, a large number of issues were detected across all of the drug interaction checkers. These were predominantly minor issues, but a considerable number of major issues were found in all but one of the checkers. Numbers of issues cannot be compared across studies, but we regard these as high numbers in view of the limited extent of the tasks applied. Qualitative analyses identified a positive correlation between the number of usability issues and the complexity of a checker. Care should be taken not to interpret this as a causal relation justifying more usability issues as a tradeoff for providing functionality. One would rather expect the basics to precede the extras. Considering their relation to basic design principles, an argument could be made that the high number of usability issues may indicate lack of systematic user-centered development. It could also result from losing track of user goals over time through incremental addition of features. Addition of features will at some point warrant redesign of a system, but limited resources may instead lead to shortsighted solutions being implemented. These can then accumulate to reduce usability and system quality. We suggest these as the most likely culprits worth examining for those drug interaction checkers identified in this paper with high numbers of usability issues.

Analyses, moreover, showed a very low degree of mobile-adaptive design. Three out of five of the checkers were essentially non-supportive of mobile devices. Adaptive design may have been a premium in the past, but is today an essential component of system quality for the Web. The proportion of mobile users on the Web is steadily increasing, at this point matching desktop users in Sweden [33]. Intermittent tasks, such as checking drug interactions, lend themselves in particular to mobile use, 
making it readily apparent that service providers cannot afford to ignore this segment of users. Lack of adaptive design forces users to handle zooming and repositioning of the viewport. This causes a constant strain on efficiency, effectiveness, and satisfaction of use, rapidly convincing users to leave and never return.

Many of the checkers also showed poor leverage of basic design principles such as visual and typographic hierarchies to guide users through the interface. Minimalist and aesthetic design utilizes consistency to highlight important information through purposefully breaking this consistency. This is a way of guiding users through complex information environments. Lack of consistency generates noise, and this noise prevents anything from standing out to the user. Usability issues relating to lack of minimalist and aesthetic design thus causes unnecessary cognitive efforts spent at interpreting the interface as opposed to attaining user goals. This leads to user dissatisfaction.

Supporting users through search suggestions, thesauri and means of managing search results was also identified as particularly important for this context. All but one of the checkers already provided search suggestions. In the only case where this was not provided, we noted this as a major usability issue in view of users having to type unfamiliar and hard-to-spell drug names without any help. Without search suggestions users would also not get early feedback that their search terms would not be recognized, and as such not yield any results. These findings of ours support Adam and Vang's [22] inclusion of search suggestions (medication pick list) as a criterion for patient usability. A natural extension of helping users type their intended queries is to help them attain the intended results even when they provide inaccurate input. In this respect we noted a lack of thesauri in all of the systems. Thesauri would be particularly useful due to the need for spelling unfamiliar words with multiple plausible spellings. As an example, the term "thyroxine" may reasonably be spelled as "thyroxin", "tyroxin", or "tyroksin" in Scandinavian languages. In addition, it would be reasonable to accept English spellings as well as popular terms such as "vitamin d" for technical terms such as "kolekalsiferol". Thesauri were not considered by Adam and Vang [22]. These means of user support are particularly important as they affect not only long-term satisfaction, but even short-term ability to retrieve information at all.

In terms of single-case analyses, nearly twice the mean number of usability issues were identified for the Swedish checker Janusmed. Even catastrophic issues were identified related to basic design principles such as providing appropriate feedback to users. The structure of the service was especially complex and incoherent. This may suggest organic growth insufficiently supported by goal-oriented and user-centered approaches. Janusmed on the other hand did provide more utility in terms of both content and functionality, employing promising interaction idioms for constructing queries. The Norwegian Interaksjoner.no took a minimalist approach, providing core functionality accompanied by clear and coherent feedback and visual hierarchy. This resulted in a particularly low number of usability issues. It failed, however, at providing patients with much-needed support in spelling difficult drug names, resulting in major usability issues in that area. Felleskatalogen.no represented a middle ground of functionality and coherence. It was one of only two services providing mobile-adaptive design. Providing necessary user support also resulted in an average amount of usability issues, but with a notable distribution towards the lower end of the severity spectrum. Legemiddelsok.no had particular issues with adaptive design, causing excessive viewport handling. The most notable trend beyond that was a complete lack of basic information welcoming users, explaining the purpose of the service, or how to use it. Medicinkombination.dk distinguished itself by providing highly accessible patient-oriented content. Its complete lack of adaptive design did not however help in providing accessibility for public audiences on mobile devices. A catastrophic issue was also identified where users might be presented with results for the previous query rather than the current. This could potentially lead to serious medical error. 


\subsection{Practical Implications}

Our findings indicate the need for developing patient-oriented drug information databases where these are currently unavailable. They also show the importance of making these databases accessible to patients through usable and user-centered interfaces. This echoes recommendations by Kusch, Haefeli, and Seidling [8]. In this paper, we also identify a cost-efficient example of how this can be done, as exemplified by Medicinkombination.dk. Simply developing such databases allows their implementation through technical frameworks already available. As shown by the Norwegian FEST database, such databases may be served openly through multiple providers. They may also be delivered to mobile applications or other innovative technologies. Beyond this, the significance of our findings lies in bringing awareness to usability problems preventing patients from attaining goals in terms of health needs and quality of life. We have done so by specifying the problems and the drug interaction checker to which they belong to, in order to help decision-makers appreciate the importance of addressing these needs as well as to facilitate action. Single-case and cross-case analyses identify themes of issues within and across the checkers evaluated. These themes inform more general areas of focus for development. They may also indicate organizational or methodological issues causing these themes to occur, such as lack of user-centered approaches. Once recognized, such issues may be addressed.

\subsection{Reliability and Validity}

Reliability of the study has been striven for by providing transparency of the procedures for data collection, analysis and interpretation. In terms of heuristic evaluations, a discussion prevails on the number of evaluators needed for reliable results. Some suggest five evaluators are enough to detect $80 \%$ of all usability issues, while others claim this is not nearly enough [26,34-36]. Nielsen [35] and Molich [36] appear to agree, however, that five evaluators are sufficient to drive useful design iteration. Nielsen adds to this that more evaluations with fewer evaluators are more efficient than fewer evaluations with more evaluators [35]. The circumstances of this study have not permitted external recruitment, and evaluations were performed by the paper's first two authors. Both were in their last term of a three-year Bachelor program in Interaction Design. Both additionally had more than four years of professional experience with user interface design. While this number of evaluators is less than what is commonly recommended, it is not without precedence [37].

Calculations were performed to estimate the reliability of the findings. The number of issues detected by each evaluator was divided by the total number of issues detected in the study. This individual detection rate was then averaged across the two evaluators for a mean probability of detection. This probability was used as a basis for making an estimation of the proportion of usability issues likely detected for the systems [26] (pp. 116-117). The calculations indicated an individual detection rate of $65 \%$, suggesting a total coverage of $87 \%$ of all usability issues for the systems. This considerably exceeds Nielsen and Landauer's [34] estimates of about 50\% coverage by two evaluators, and also exceeds the $80 \%$ commonly sought in usability evaluations. We suggest that this high reliability is a result of the limited scope of tasks applied across the five systems evaluated.

Other means taken to ensure reliability were triangulation of qualitative and quantitative data sources, as well as having researchers work independently and check each other's findings for researcher triangulation. The transparency of procedures has been strived for through accurate description of the methodology and choice thereof in the methodology section.

Validity has been strived for by providing rich, thick description of the findings, as well as by triangulating data sources. Usability is defined as contingent upon users' contextualized and lived experience. Expert-based methods such as heuristic evaluations contain inherent risk of disconnect from this experience. On the other hand, Molich [36] found usability issues identified through heuristic evaluations to rarely provide false positives. Nonetheless, the evaluations must be understood as conditioned by presumptions about behaviors of the target audience. These were based on general populations rather than grounded on user-centered research. Audiences for these drug interaction 
checkers are known to be broad, but also to contain higher proportions of elderly users and other segments with particular need for drug information [11]. Potential variations in behavior based on this factor have not been accounted for in this paper. Addressing this could be done through triangulation by contextually situated and user-centered methods, such as usability testing with targeted participants or involving targeted participants as lead users. Presumptions about the audience also affected severity assessments in terms of the anticipated frequency of occurrence. This could potentially affect their validity. The absence of user account functionality might for example have been a more prominent theme, had evaluations proceeded from an assumption of regularly returning users.

Adam and Vang [22] assessed patient usability in terms of presence or absence of alert icons, color coding, severity rating scale, medication pick list and the ability to save a user profile. Whereas their grading scale would have awarded the checkers sampled in this paper with full scores on all of the factors of alert icons, color coding, and severity rating scales, our heuristic evaluations identified even catastrophic usability issues arising from the very same features. We found that not only medication pick lists are needed for usability, but also handling of alternate spellings and misspellings. We also found that requiring a login to a user profile can be detrimental to usability depending on assumptions about the target audience and the specific implementation. This highlights limitations of the approach chosen by Adam and Vang [22] compared to the use of heuristic evaluations to show a more nuanced picture of usability.

\subsection{Limitations}

This paper applied issue-based metrics for their potential for open-ended exploration of usability within and across multiple services available in the Scandinavian market. They were also chosen for their capacity to inform actionable insights. The exclusion of performance metrics and self-reported satisfaction limits the extent to which overall usability could be assessed and quantified. This was a choice made for delimiting the scope of the study, eliminating the need for extensive recruitment and user testing.

Although we have adopted a patient-oriented perspective, findings were rarely found to pertain to patients to the exclusion of professionals. Even content-related findings, such as use of acronyms and technical terminology, could be argued as relevant to professionals in training, or to those less familiar with certain medical topics. A patient-oriented approach, as such, might be suggested as a kind of lead user approach, highlighting overlooked needs that nonetheless benefit primary audiences.

\section{Conclusions}

This paper has explored the availability of patient-oriented drug interaction checkers in the Scandinavian countries of Denmark, Norway, and Sweden. It has also explored the prevalence and characteristics of usability problems in these checkers which prevent patients from benefiting from them. In our study, we identified six such checkers: three Norwegian, two Danish, and one Swedish. The service providers were national authorities, drug industry associations and privately owned eHealth businesses. All of the checkers served content from national authoritative sources. All except one of the checkers primarily targeted professional audiences for clinical decision support, while at the same time allowing public access. Only Medicinkombination.dk targeted patient audiences with patient-oriented and highly readable content.

A large amount of usability issues was detected across all of the drug interaction checkers evaluated, and a considerable number of major issues were identified in all but one of the checkers. Three catastrophic usability issues were detected, each deemed catastrophic for its potential to lead to serious medical errors. Although the numbers of usability issues cannot be compared across studies, these should be considered high in view of the limited extent of the tasks. Catastrophic issues signify issues unacceptable in publicly released systems, but the large amount of minor issues also suggests insufficient systematic development and testing. 
The qualitative analyses identified four cross-case themes of usability issues: there was a notable lack of mobile-adaptive design, there was a general lack of patient-oriented content, there was a general lack of adherence to basic design principles, and there was a clear positive correlation between system complexity and number of usability issues.

Our findings show a beginning towards accommodating patient needs, but also show Scandinavian audiences faced with a limited number of drug interaction checkers primarily targeting medical professionals. These are known to be used by patients for their utility but fail to accommodate them in terms of information and system quality. Empowering patients to participate in decision-making affecting their personal health and quality of life calls for developing patient-oriented drug information databases where these do not currently exist. These need to be presented through clear, coherent and supportive user interfaces, acknowledging the behaviors of the patients interacting with them. Developers and decision-makers should ensure that future development initiatives are conducted based on systematic goal-oriented and user-centered design approaches and research, to ensure that drug interaction-checkers inform patients according to their own needs and abilities rather than implementation-centric or arbitrarily emergent mental models.

\section{Future Research}

In accordance with the findings of this paper, we suggest that further research should focus on exploring patient needs and behaviors in accessing drug-related information. Whereas Kusch, Haefeli and Seidling [8] approach this in terms of topics desired by patients, future research should focus more on qualitative accounts of how this information is actually accessed and used. This would provide strong foundations for future development of patient-oriented information databases. It could also inform the development of mobile applications taking advantage of the individualization, mobility and multi-functionality of mobile devices. We also suggest future studies involving representative users to validate and complement the findings of both this paper and previous research on this topic.

Author Contributions: Conceptualization, D.V., E.J.A. and M.F.; methodology, investigation and data curation, D.V. and E.J.A.; formal analysis, D.V.; writing-original draft preparation, D.V. and E.J.A.; writing-review and editing, D.V.; visualization, D.V. and E.J.A.; supervision, M.F.; project administration, E.J.A., D.V. and M.F. All authors have read and agreed to the published version of the manuscript.

Funding: This research received no external funding.

Conflicts of Interest: The authors declare no conflict of interest.

\section{Appendix A Heuristic Evaluation Findings for All Systems}

The Heuristic Evaluation Findings document contains the full details of the usability issues detected in the study. The issues are recorded in table format by checker evaluated. Task number and screenshots serve to locate the issue. Detailed descriptions are provided along with severity ratings and the heuristics found applicable. The findings are accessible from the following link: https://docs.google. com/document/d/13rxSRk0TP-SVyubnfC8OJjaM_4ZAEKkoVHsoUGPnQ84/edit?usp=sharing

\section{References}

1. Patient Safety-Data and Statistics. Available online: https://www.euro.who.int/en/health-topics/Healthsystems/patient-safety/data-and-statistics (accessed on 10 September 2020).

2. Säfholm, S.; Bondesson, $\AA$.; Modig, S. Medication Errors in Primary Health Care Records; a Cross-Sectional Study in Southern Sweden. BMC Fam. Pract. 2019, 20, 110. [CrossRef] [PubMed]

3. Thomsen, L.A.; Winterstein, A.G.; Søndergaard, B.; Haugbølle, L.S.; Melander, A. Systematic Review of the Incidence and Characteristics of Preventable Adverse Drug Events in Ambulatory Care. Ann. Pharmacother. 2007, 41, 1411-1426. [CrossRef] [PubMed]

4. Cascorbi, I. Drug Interactions-Principles, Examples and Clinical Consequences. Dtsch. Ärzteblatt Int. 2012, $109,546-556$. 
5. Åstrand, E.; Åstrand, B.; Antonov, K.; Petersson, G. Potential Drug Interactions During a Three-Decade Study Period: A Cross-Sectional Study of a Prescription Register. Eur. J. Clin. Pharmacol. 2007, 63, 851-859. [CrossRef] [PubMed]

6. Hovstadius, B.; Hovstadius, K.; Åstrand, B.; Petersson, G. Increasing Polypharmacy-An Individual-Based Study of the Swedish Population 2005-2008. BMC Clin. Pharmacol. 2010, 10, 1-8. [CrossRef]

7. Castro, E.M.; Van Regenmortel, T.; Vanhaecht, K.; Sermeus, W.; Van Hecke, A. Patient Empowerment, Patient Participation and Patient-Centeredness in Hospital Care: A Concept Analysis Based on a Literature Review. Patient Educ. Couns. 2016, 99, 1923-1939. [CrossRef] [PubMed]

8. Kusch, M.K.P.; Haefeli, W.E.; Seidling, H.M. How to Meet Patients' Individual Needs for Drug Information-A Scoping Review. Patient Prefer. Adherence 2018, 12, 2339-2355. [CrossRef] [PubMed]

9. Böttiger, Y.; Laine, K.; Andersson, M.L.; Korhonen, T.; Molin, B.; Ovesjö, M.-L.; Tirkkonen, T.; Rane, A.; Gustafsson, L.L.; Eiermann, B. SFINX-A Drug-Drug Interaction Database Designed for Clinical Decision Support Systems. Eur. J. Clin. Pharmacol. 2009, 65, 627-633. [CrossRef] [PubMed]

10. Janusmed. Available online: https://janusmed.sll.se (accessed on 1 June 2020).

11. Andersson, M.L.; Böttiger, Y.; Lindh, J.D.; Wettermark, B.; Eiermann, B. Impact of the Drug-Drug Interaction Database SFINX on Prevalence of Potentially Serious Drug-Drug Interactions in Primary Health Care. Eur. J. Clin. Pharmacol. 2013, 69, 565-571. [CrossRef] [PubMed]

12. Nörby, U.; Källén, K.; Shemeikka, T.; Korkmaz, S.; Winbladh, B. Pregnant Women's View on the Swedish Internet Resource Drugs and Birth Defects Intended for Health Care Professionals. Acta Obstet. Gynecol. Scand. 2015, 94, 960-968. [CrossRef] [PubMed]

13. Reolon, M.; Lacerda, T.; Krone, C.; Gresse von Wangenheim, C.; Xafranski, J.; Nunes, J.; Von Wangenheim, A. Usability Heuristics for Evaluating Healthcare Applications for Smartphones: A Systematic Literature Review; Technical Report INCoD/GQS.01.2016.E.; INCoD—Brazilian Institute for Digital Convergence: Campinas, Brazil, 2016.

14. World Health Organization. mHealth: New Horizons for Health through Mobile Technologies: Second Global Survey on eHealth; Global Observatory for eHealth Series Volume 3; World Health Organization: Geneva, Switzerland, 2011.

15. How to Kill Patients Through Bad Design. Available online: https://www.nngroup.com/articles/medicalusability/ (accessed on 29 May 2020).

16. Koppel, R.; Metlay, J.P.; Cohen, A.; Abaluck, B.; Localio, A.R.; Kimmel, S.E.; Strom, B.L. Role of Computerized Physician Order Entry Systems in Facilitating Medication Errors. JAMA 2005, 293, 1197-1203. [CrossRef] [PubMed]

17. Schnall, R.; Cho, H.; Liu, J. Health Information Technology Usability Evaluation Scale (Health-ITUES) for Usability Assessment of Mobile Health Technology: Validation Study. JMIR Mhealth Uhealth 2018, 6, e4. [CrossRef] [PubMed]

18. Zhou, L.; Bao, J.; Setiawan, I.; Saptono, A.; Parmanto, B. The mHealth App Usability Questionnaire (MAUQ): Development and Validation Study. JMIR Mhealth Uhealth 2019, 7, e11500. [CrossRef] [PubMed]

19. Beauchemin, M.; Gradilla, M.; Baik, D.; Cho, H.; Schnall, R. A Multi-step Usability Evaluation of a Self-Management App to Support Medication Adherence in Persons Living with HIV. Int. J. Med. Inform. 2019, 122, 37-44. [CrossRef] [PubMed]

20. Stonbraker, S.; Cho, H.; Hermosi, G.; Pichon, A.; Schnall, R. Usability Testing of a mHealth App to Support Self-Management of HIV-Associated Non-AIDS Related Symptoms. Stud. Health Technol. Inform. 2018, 250, 106-110.

21. Jaspers, M.W. A Comparison of Usability Methods for Testing Interactive Health Technologies: Methodological Aspects and Empirical Evidence. Int. J. Med Inform. 2009, 78, 340-353. [CrossRef]

22. Adam, T.J.; Vang, J. Content and Usability Evaluation of Patient Oriented Drug_Drug Interaction Websites. Amia Annu. Symp. Proc. 2015, 2015, 287-296.

23. 10 Usability Heuristics for User Interface Design. Available online: https://www.nngroup.com/articles/tenusability-heuristics/ (accessed on 1 July 2020).

24. Monkman, H.; Kushniruk, A. A Health Literacy and Usability Heuristic Evaluation of a Mobile Consumer Health Application. Stud. Health Technol. Inform. 2013, 192, 724-728.

25. Bertini, E.; Catarci, T.; Dix, A.; Gabrielli, S.; Kimani, S.; Santucci, G. Appropriating Heuristic Evaluation for Mobile Computing. Int. J. Mob. Hum. Comput. Interact 2009, 1, 20-41. [CrossRef] 
26. Tullis, T.; Albert, B. Measuring the User Experience, 2nd ed.; Morgan Kaufmann: Waltham, MA, USA, 2013.

27. Sharp, H.; Preece, J.; Rogers, Y. Interaction Design: Beyond Human-Computer Interaction, 5th ed.; Wiley: Indianapolis, IN, USA, 2019.

28. Wilson, C. User Interface Inspection Methods: A User-Centered Design Method; Morgan Kaufmann: San Francisco, CA, USA, 2014.

29. Creswell, J.W.; Creswell, J.D. Research Design: Qualitative, Quantitative E Mixed Methods Approaches, 5th ed.; Sage: Los Angeles, CA, USA, 2018.

30. Similarsites.com-Easily Explore Alternative Websites. Available online: https://www.similarsites.com/ (accessed on 22 May 2020).

31. Nielsen, J.; Molich, R. Heuristic Evaluation of User Interfaces. In Proceedings of the SIGCHI Conference on Human Factors in Computing. Systems, Seattle, WA, USA, 1-5 April 1990; pp. 249-256.

32. Nielsen, J. Enhancing the Explanatory Power of Usability Heuristics. In Proceedings of the SIGCHI Conference on Human Factors in Computing. Systems, Boston, MA, USA, 24-28 April 1994; pp. 152-158.

33. Desktop vs Mobile vs Tablet Market Share Sweden | StatCounter Global Stats. Available online: https://gs.statcounter.com/platform-market-share/desktop-mobile-tablet/sweden/\#monthly-201504-202004 (accessed on 1 June 2020).

34. Nielsen, J.; Landauer, T. A Mathematical Model of the Finding of Usability Problems. In Proceedings of the SIGCHI Conference on Human Factors in Computing. Systems, Amsterdam, The Netherlands, 24-29 April 1993; pp. 206-213.

35. How Many Test Users in a Usability Study? Available online: https://www.nngroup.com/articles/how-manytest-users/ (accessed on 1 July 2020).

36. Molich, R. Are Usability Evaluations Reproducible? Interactions 2018, 25, 82-85. [CrossRef]

37. Law, L.C.; Hvannberg, E.T. Complementarity and Convergence of Heuristic Evaluation and Usability Test: A Case Study of UNIVERSAL Brokerage Platform. In Proceedings of the Second Nordic Conference on Human-Computer Interaction, Aarhus, Denmark, 19-23 October 2002; pp. 71-80.

Publisher's Note: MDPI stays neutral with regard to jurisdictional claims in published maps and institutional affiliations.

(C) 2020 by the authors. Licensee MDPI, Basel, Switzerland. This article is an open access article distributed under the terms and conditions of the Creative Commons Attribution (CC BY) license (http://creativecommons.org/licenses/by/4.0/). 